\title{
LAS CONSTITUCIONES DE 1812
}

\section{CARLOS PALADINES}

Pontificia Universidad Católica del Ecuador 


\section{Resumen}

La ponencia presenta un 'universo discursivo' de finales del sistema colonial e inicios de la vida republicana; un conjunto de textos predominantemente de carácter constitucional que tuvieron especial relevancia en el proceso independentista de la Audiencia de Quito y en la conformación del Estado moderno en el Ecuador. También se muestra la génesis, los principales actores, las tesis o categorías emblemáticas de esta documentación y su carácter pionero, incluso en relación con la Constitución de Cádiz; pero en su contexto, un sistema productivo fraccionado en tres zonas económicas que no lograban integrarse, en su paso del sistema colonial a nuevas fuerzas y relaciones sociales de producción. Además se trata de mostrar que anterior a la denominada Constitución Quiteña de 1812 se dio la Carta Magna de 1809 que aún no ha sido debidamente ni investigada ni valorada.

"Pues realmente no hay ninguna otra ocupación en la que la virtud humana se aproxime más de cerca a la función augusta de los dioses que la de fundar nuevos Estados o preservar los ya existentes". ${ }^{1}$

\section{Marco teórico y metodológico ${ }^{2}$}

1 Cicerón. La República, Argentina, Edit. Aguilar, 1967, p. 32.

Tomando en cuenta las recomendaciones metodológicas y filosóficas del Prof. Arturo Roig, podría afirmarse que no hay un solo discurso -micro discursos- sino más bien una diversidad discursiva macro discursos- compuesta de discursos ocultos, de discursos contrarios, de líneas discursivas, de discursos referidos y anti-discursos,... parte de un sistema de conexiones o estructura histórica, que conferiría sentido a las partes y de la cual los discursos no son más que su reformulación. Por todo ello el discurso no puede ser analizado en forma aislada sino como integrante de un grupo de textos que constituirían un universo discursivo, totalidad discursiva de una comunidad humana concreta, en el seno de la cual
El propósito de esta "conversación" es presentar un 'universo discursivo' de finales del sistema colonial e inicios de la vida republicana: 1770-1845; un conjunto de textos predominantemente de carácter constitucional, necesarios ellos aunque no suficientes, para mostrar la génesis del Estado moderno en el Ecuador. A partir de estos documentos, solo inteligibles al interior de un "universo discursivo" y su contexto, se tratará de desplegar los avances que en el campo del pensamiento jurídico y político se dieron para concretar la urgente necesidad de darse un gobierno propio. Por supuesto, esta aspiración no brotó de la noche a la mañana. Quito tenía ya a su haber una larga historia de reclamos y levantamientos, y el desarrollo teórico requerido para transformarse en Luz de América gracias al Primer Grito de autonomía e independencia de España. ${ }^{3}$

se reproduce el contexto y el sistema de contradicciones del entorno social. En diversas ocasiones he abordado directamente el tema metodológico. Cfr. Carlos Paladines, "Notas sobre metodología de investigación del pensamiento ecuatoriano", México, Rev. Latinoamérica, Anuario de Estudios Latinoamericano, No. 11, 1978; "Aproximaciones a la lectura del universo discursivo" (funciones, estrategias y modelos), en: Cortinas de humo, Ecuador, Edt. CCE, 2008; "Metodología y filosofía del pensamiento latinoamericano en Arturo Roig". Pontificia Universidad Católica del Ecuador, 2012. También hemos trabajado bajo similar perspectiva en la reconstrucción de la Historia de la Educación y el Pensamiento Pedagógico Ecuatorianos, IV Edición, Vol. I y II, Editor Municipio del Distrito Metropolitano de Quito, 2011.

${ }^{3}$ Se ha bautizado a la Revolución de Quito como el Primer Grito de Independencia sin desconocer los levantamientos y rupturas con la madre patria que se suscitaron inclusive ese mismo año de 1809 en Chuquisaca o en Montevideo en 1808. La Revolución de Quito se diferenció de otras actividades de resistencia a España, en cuanto ella no solo desarrolló actos de violencia o protesta contra España sino además de ruptura de la soberanía representada por el monarca español, de cambio de las autoridades, las instituciones y las forma de gobierno del Estado colonial. "Esta fue, según el historiador Salvador Lara, la originalidad, el peso específico y la trascendencia del movimiento quiteño de agosto de 1809". Mayores detalles puede verse en Jorge Salvador Lara, "Trascendencia universalista del 10 de agosto de 1809”, en Rev. del Museo Histórico, No. 69, 2010, p. 
Por otra parte, sería incompleta una visión de los primeros pasos de conformación del Estado que se redujese solo al examen del andamiaje constitucional -el texto- ${ }^{4}$ y no estableciese las debidas y complejas relaciones que se entretejen entre las partes y la totalidad, -el contexto-. Los textos no son autónomos de sus contextos y por ello se requiere mostrar las mutuas vinculaciones e interrelaciones con los

7. Camilo Destruge, Controversia histórica sobre la iniciativa de la intendencia americana, refutación de un alegato, Guayaquil, Librería e Imprenta Gutenberg de Uzcátegui, 1909.

"Este "universo discursivo" estaría integrado por los siguientes ya históricos documentos:

$>$ Eugenio Espejo: Voto de un Ministro Togado, del 7 de marzo de 1792; las Memorias sobre el corte de quinas, de similar fecha, y el periódico Primicias de la Cultura de Quito del 5 de enero de 1792 al 29 de marzo de 1792.

$>$ Los Estatutos de la Sociedad de Amigos del País de la Audiencia de Quito, de marzo 17 de 1792;

$>$ El Expediente sobre los escandalosos efectos que ha producido la libertad filosófica en la Universidad de Santo Tomás, de julio 5 de 1803;

$>$ El Discurso de Instalación de la Sociedad de Amigos del País, del Virreinato de Santa Fe, de diciembre 10 de 1801;

$>$ El Acta de Constitución de la Junta Suprema Gubernativa del Reino de Quito, del 10 de agosto de 1809 y sus documentos anexos;

$>$ El Proyecto de Constitución de Calixto Miranda, de enero de 1812;

$>$ La Constitución quiteña de febrero 15 de 1812;

$>\quad$ La Constitución de Cádiz de marzo 19 de 1812;

$>$ La Oración fúnebre que el Dr. Miguel Antonio Rodríguez pronunció en las exequias de los que murieron en el cuartel el 2 de agosto de 1810 y la documentación sobre la Revolución de Quito y los procesos seguidos a los próceres de la Independencia: 1808-1812, y

$>$ Los Discursos de José Mejía y José Joaquín de Olmedo en la Corte de Cádiz, 1810-1813.

$>$ La Constitución de la Gran Colombia, Cúcuta 1821 y 1830;

$>$ La Constitución del Ecuador en su fase inicial: 1830- 1835-1843-1845. factores que jugaron papel decisivo en su formulación.

Si bien los documentos constitucionales no encierran mayores desarrollos sobre aspectos económicos o financieros, fueron parcos en relación al sistema productivo y no realizaron una clara ruptura con el Estado colonial; esto no significa que hubiesen estado radicalmente cerrados a demandas de orden material, por ejemplo, al sentido reclamo por "libertad de comercio". La teoría y la práctica impulsaron a los más diversos actores tanto de la "intelectualidad quiteña", como del comercio y la agricultura e incluso a nivel de algunas autoridades a oponerse al mantenimiento de instituciones o leyes que trababan la circulación de bienes y personas en el mercado. Lo cual no obsta reconocer que sobre las cenizas del Estado colonial no se lograron levantar estructuras estatales y políticas radicalmente diferentes y tampoco se implementaron de inmediato aquellas instituciones y mecanismo que hubiesen permitido levantar las condiciones necesarias para disponer de ciudadanos con los bienes de instrucción, propiedad y trabajo propios de un Estado moderno.

\section{Génesis de un universo discursivo y de sus actores}

No es posible determinar con exactitud matemática cuándo se pusieron a debate y quiénes defendieron o rechazaron los primeros planteamientos sobre la modernidad en la Audiencia de Quito, pero consta que en las primeras décadas del S. XVIII, por obra de Magnin, Hospital, Carvajal, Rodríguez,... se abrieron paso en la universidad los primeros planteamientos referentes a la 'nueva ciencia', a los sistemas del mundo, al movimiento, a la 
caída de los cuerpos, las manchas solares,... de que habría de nacer la física moderna.

Tampoco hoy se puede determinar con exactitud quiénes presentaron los primeros planteamientos políticos de corte moderno, pero consta que a partir de diversos trabajos de José Pérez Calama, Eugenio Espejo, José Mejía,... se abrieron las puertas a informes sobre la crisis y decadencia del sistema de estudios, de la economía y finanzas, de la agricultura y las industrias de la Audiencia de Quito. También se hicieron presentes los primeros balbuceos sobre la soberanía del pueblo, la quiteñidad, el orgullo nacional, la valoración de lo propio, la superación del mercantilismo por el librecambismo, la nueva concepción sobre lo que era 'natural', la felicidad, la razón,... conceptos y categorías que habían de servir años más tarde para la formular las primeras constituciones quiteñas.

En aquella época también aportaron tanto a la ruptura del edifico escolástico como a la crítica al sistema colonial una serie de informes tanto de las autoridades: Virrey de Santa Fe, Presidente y Obispo de la Audiencia, como de civiles o religiosos que gozaban de prestigio en determinadas áreas: Calama, Espejo, Navarro,... sobre el estado calamitoso, por decir lo menos, de las principales estructuras de la Audiencia. Ellos entregaron una detallada descripción negativa y crítica del sistema colonial que habría de ser años más tarde la pólvora con la que se prendió el discurso anti español y al mismo tiempo el impulso requerido para la búsqueda de solución a tantos males. La Sociedad de Amigos del País o Escuela de la Concordia (1792) presentó las recetas que de implementarse lograrían levantar al enfermo de su estado de postración. La Sociedad correspondiente al Virreinato de
Santa Fe inició actividades una década después: 1801.

Sin entrar en un estudio pormenorizado, tarea que fue asumida en otros trabajos, ${ }^{5}$ se expondrán sucintamente algunos conceptos claves, toda vez que ellos alimentaron los documentos a que hemos hecho referencia, fueron base de la redacción de las constituciones quiteñas, en plural; $y$, en buena medida, aún no han perdido actualidad. Sin desconocer que tales categorías más que conceptos hundan raíces en una matriz productiva como ya se ha señalado.

Mas estos documentos guardan unidad no solo en cuanto a sus contenidos o temáticas y a sus propósitos y fines, sino también en lo relativo a sus actores: integrantes del movimiento ilustrado y algunos de ellos precursores, próceres de la independencia y víctimas de la represión española desatada en 1810 por las autoridades del Virreinato de Lima y de Santa Fe. Un movimiento de larga duración fue la base de un proceso exitoso en medio de sus limitaciones: la primera, segunda y tercera generación ilustrada que a lo largo de prácticamente un siglo: 1750-1850, acariciaron sus sueños, supieron hacerlos realidad en buena medida y asistieron a su fase de debilitamiento y caída. Algunos nombres resultaron emblemáticos en cada una de estas generaciones: Magnin, Hospital y Carvajal; Espejo, Rodríguez y Mejía; Rocafuerte, Olmedo y Hall. Por supuesto, algunos de ellos recogieron la antorcha de manos del anterior equipo y la entregaron engrandecida a sus discípulos, quienes a su

\footnotetext{
5 Ver, Juan Magnin, Descartes Reformado (Carlos Paladines: Estudio Introductorio), Quito, Edit. Fondo de Salvamento del Patrimonio Cultura, FONSAL, 2009. Carlos Paladines, Pensamiento Ilustrado Ecuatoriano, Ecuador, Edit. Corporación Editora Nacional y Banco Central del Ecuador, 1979.
} 
vez enriquecieron el legado recibido, crearon las instituciones que hacían falta para la concreción del Estado moderno y esa rica herencia la supieron depositar en nuevas manos.

Pero no solo los contenidos, los actores o las instituciones, las condiciones materiales fueron parte del escenario o contexto de los textos bajo análisis, también la estrategia fue compartida y ella fue diseñada en clara respuesta a los diversos acontecimientos o posiciones que adoptó la Corona española en las últimas décadas del siglo XVIII y que varió radicalmente a inicios del XIX, de modo especial de cara a la invasión napoleónica. Con la Constitución de la Sociedad de Amigos del País o Escuela de la Concordia se delineó una estrategia proyecto autonomista- y a raíz de la prisión y muerte de Espejo y posteriormente con la masacre de los próceres del 10 de agosto de 1809 , cambió radicalmente la misma, dando paso a un proyecto independentista, período y creación de un nuevo Estado.

También la opinión pública, al igual que las instituciones y medios de información de aquella época se vieron compelidos a readecuar su acción a las nuevas circunstancias. Primicias de la Cultura de Quito, órgano de expresión de la Sociedad de Amigos del País cerró su edición a pocos meses de iniciada su tarea; pero a inicios de siglo florecieron numerosos periódicos que rompieron el cerco de la comunicación, básicamente en manos de las órdenes religiosas, permitiendo ampliar su círculo y democratizar la información con la participación de actores civiles. Así se inició el proceso de secularización de la opinión pública, de cuño moderno.

\section{Las primeras constituciones}

La Carta Magna, 6 término con que he bautizado al Acta de Constitución de la Junta Suprema Gubernativa del Reino de Quito del 10 de agosto de 1809, unida al Manifiesto de la Junta Suprema de Quito al Público, al Manifiesto del Pueblo de Quito de la misma fecha y al Manifiesto de la Suprema Junta de Quito a la América del 16 de agosto han sido y pueden ser asumidos como los primeros documentos de origen del Estado de Quito. ${ }^{7}$

Manuel Rodríguez de Quiroga, desde la cárcel, bautizó a estos documentos con el nombre de Constitución, que de serlo sería la primera que tuvo el país, dos años antes de la de 1812 reconocida como la Constitución Quiteña primera y dos décadas antes de la primera Constitución que se tuvo como República del Ecuador: 1830. Rodríguez de Quiroga también informó sobre los detalles de su elaboración en casa de Ascázubi, de boca de Morales que la dictó y Arenas que la escribió; pero sobre todo realizó su primer estudio y defensa, al señalar que se trataba de una verdadera

\footnotetext{
${ }^{6}$ Por extensión, se suele denominar Carta Magna a la Constitución primera de un Estado, norma suprema y base de su ordenamiento jurídico, administrativo e institucional.

${ }^{7}$ En los años sesenta el historiador Jorge Salvador Lara desbrozó este camino que aún permanece poco explorado. Cito in extenso por la importancia del texto: "En casi todos los tratados sobre derecho constitucional ecuatoriano suele mencionarse como primer estatuto jurídico de nuestra nación aquel que don Celiano Monge, su descubridor llamó Documento de Oro: la Constitución quiteña de 1812. Sin embargo, la verdad es que los mismos próceres de 1809 estudiaron, redactaron, suscribieron, promulgaron y juraron su propia Constitución. Ella no fue otra que el Acta del Pueblo, suscrita en el Palacio Real de Quito, el 10 de agosto de 1809 , mediante la cual se derrocó al gobierno español, se constituyó la Junta Suprema Gubernativa de Quito, se estableció su estructura política y se sentaron las bases jurídicas del nuevo Estado". Jorge Salvador Lara, "La primera Constitución Politica de la nación ecuatoriana: la del 10 de Agosto de 1809", en I. Municipio de Quito, Rev. del Museo Histórico, No. 69,2010 , p. 793. También puede verse en La Patria Heroica, Quito, 1961, pp.188 ss.
} 
Constitución, no tanto por sus aspectos formales, cuanto por la declaración sobre el depositario del "Poder o Autoridad Suprema" y su capacidad para establecer un nuevo Estado de gobierno, aunque en calidad interina, como también por el proceso de aprobación y ratificación de parte de un numeroso Congreso. ${ }^{8}$

Es del caso subrayar que, tanto los peculiares textos: Actas y Manifiestos del año diez, como el "Pacto solemne de Sociedad y Unión entre Provincias que forman el Estado de Quito" del año doce, reconocido como la Constitución Quiteña, -Decreto (Documento) de Oro, a decir de Celiano Monge, quien fue el primero en darlo a conocer, en 1913-, ${ }^{9}$ coinciden en el propósito de dotar a Quito de un nuevo Estado o forma de ejercer el poder; es decir, levantar una nueva entidad que organice la vida política en ruptura con la simplicidad de la organización absolutista o colonial, lo cual se juzgó viable mediante un sistema de contra pesos en cuanto a los poderes; la distribución de competencias y diferenciación de funciones y atributos en las autoridades, camino para "despersonalizar" o sustituir el poder absoluto del monarca o del presidente de la Audiencia. ${ }^{10}$

Se aspiraba de este modo a preservar al individuo de la omnipotencia de la autoridad colonial y de sus abusos; a frenar el poder omnímodo de las autoridades, que a nivel del monarca español y de sus representantes en suelo americano los

\footnotetext{
${ }^{8}$ Ver, Roberto Andrade, Defensa de Rodríguez de Quiroga, en Historia del Ecuador, Imp. Guayaquil, TII, pp. 554-651, s.f.

${ }^{9}$ Ver, Celiano Monge, "Documento de Oro, Constitución del Estado de Quito 1811-1812”. Casa Editorial de Ernesto C. Monge, Quito, 1913.

${ }^{10}$ Ver, Rodrigo Borja Cevallos, Derecho Político y Constitucional, CCE, Quito, 1971, t. I, p. 185 y ss. t. II, p. 441.
}

transformaba en déspotas que eran reyes, legisladores y jueces al unísono. Además, se abría las puertas a la "voluntad general" a través de sus representantes, llamados ellos a tener como norte la consecución de la felicidad pública, la salud de la República, que es la Ley Suprema. Seamos felices y dichosos, años antes lo propusieron las banderitas de Quito: "Libres seremos bajo la cruz salvadora, después de haber alcanzado el propósito santo de gloria y felicidad", que la tradición ha atribuido a Espejo. ${ }^{11}$

Mas estos primeros textos constitucionales no solo abrieron las puertas a las más avanzadas tesis que en aquel tiempo se debatían y se experimentaban a nivel mundial, especialmente en Francia y Estados Unidos de Norteamérica, también apuntalaron, desde el campo jurídico, al proceso de modernización del Estado y de la sociedad, odisea en la cual se ha visto embarcado el Ecuador por ya más de dos siglos sin lograr aún Ilegar a puerto definitivo o seguro. Los intentos de modernización han sido múltiples, variados y frustrantes.

En cuanto a la apertura a concepciones modernas de la Constitución de 1809 y de la de 1812, valga recordar que Espejo al igual que Quiroga, Quiñones y Cienfuegos, Miguel Antonio Rodríguez eran personas versadas en las fuentes francesas y españolas últimas y son múltiples sus referencias a Rousseau, Montesquieu. Feijoo, por citar algunos. Tampoco falta en ellos: Calama, Quijano, Quiroga, Rodríguez de Soto, Montufar, Juan Larrea referencias a las luchas independentistas de los Estados Unidos de Norteamérica. Quijano reconoció el influjo de la Declaración de Independencia de Nor-

\footnotetext{
${ }^{11}$ Cfr. Manifiesto de la Suprema Junta de Quito a la América; Relación de los sucesos acaecidos en Quito, del 10 al 17 de agosto de 1809.
} 
teamérica, del 4 de julio de 1776 o de la Constitución de los Estados Unidos de 1787, en los patriotas integrantes de la primera y segundas juntas de Quito, de 1809 y 1810 hasta 1812. Incluso se podría establecer similitudes entre la estructura de una y otra. Ambas Constituciones se organizan tomando en cuenta la división de poderes. ${ }^{12}$

En relación a la generación de fórmulas y propuestas para responder a situaciones específicas o propias de la hora y de nuestra idiosincrasia, la investigación aún no ha sido mayor. Se ha concentrado la atención en la vinculación de los textos constitucionales con las circunstancias propias del proceso independentista o de separación de la "madre patria" y no se ha sabido rescatar las virtualidades que encerraban para la generación de una nueva entidad política, tan nueva que no había modelo o ejemplo a imitar en toda Hispanoamérica y había que reemplazar a instituciones del sistema colonial vigentes a lo largo de varios siglos. ${ }^{13}$

\footnotetext{
${ }^{12}$ Ver, Ekkehart Keeding, Surge la nación, La Ilustración en la Audiencia de Quito. Quito, Banco Central del Ecuador, 2008. Se señala, en el acápite: "Índice de nombres propios y de materias: Estados Unidos de Norteamérica", con mayores detalles el influjo del proceso independentista norteamericano en autores de la Audiencia de Quito. También puede verse, Carlos Paladines: "Ilustración francesa e ilustración ecuatoriana", en Nación, Estado y Conciencia Nacional, Ecuador, Corporación Editora Nacional, 1992, pp. 53SS.

${ }_{13}$ En palabras de Fabián Corral: "La Constitución quiteña, entendida usualmente como una declaración de independencia, no se agota en ese hecho histórico. Es, ante todo, un acto de fundación; es la expresa manifestación soberana de la conformación de una entidad política. Es la culminación del proceso que se inició el 10 de agosto de 1809, que debe reivindicarse, además, como la primera carta política del Ecuador, cuya originalidad corre a la par con la dialéctica conceptual de los fundadores: la élite quiteña que en el preámbulo del documento articuló una visión compleja, inusual y no por eso menos interesante de los fundamentos de la nueva autoridad, es decir, de la legitimidad del mando republicano que iba a sustituir al dominio colonial. Ver, "La Constitución quiteña de 1812”, Diario El Comercio, jueves 09/08/2012.
}

El texto de 1812 dedicó varios artículos -tal vez sea este el campo en que el articulado fue abundante- a la organización y juego del nuevo poder, tomando en cuenta sus posibles abusos, insistiendo en las barreas de protección contra la arbitrariedad del mismo, en el equilibrio en el número de representantes por provincias, en el tiempo de duración del ejercicio de los cargos públicos, en la prohibición de nombrar parientes dentro del cuarto grado de consanguinidad, etc. Recomendaciones que no han perdido valor en el presente.

Desde el artículo siete al veintiuno se detaIla la estructura del poder interno que era necesario organizar para el gobierno eficiente de la flamante república. Era el poder desquiciado por décadas de lucha incluso armada lo que se juzgaba urgente reconstituir; era el realismo político la consecuencia natural de años de duras experiencias sufridas sin lograr cambiar las estructuras básicas coloniales. Igualmente, la transformación de las leyes patrias, la reforma tanto del código civil como del criminal y de los reglamentos de todos los ramos de la administración política y civil, aunque su proceso de reformulación y adaptación a las nuevas realidades fue por demás lento y tardó varias décadas en concretarse.

Se dieron así los primeros pasos, no solo para poner fin a un sistema oprobioso y de centenaria vigencia sino también para diseñar y crear los nuevos aparatos del nuevo estado que debía asentarse en los territorios de la Audiencia de Quito y que los asambleístas supieron delimitar con el debido tino, dada la ambigua situación de dependencia de la Audiencia en relación a los dos vecinos: el Virreinato de Lima y el de Bogotá. 
Por otra parte, el nacimiento de la nueva instancia política se hizo con la concurrencia de una población que también ella requería de clara delimitación. La élite ilustrada, los "criollos", no se sentían españoles, rechazaban a los "españoles europeos" y no identificaban su territorio como parte de la península. En las últimas décadas del siglo XVIII la élite quiteña juzgaba que su territorio y su pueblo se destacaban por la belleza y la riqueza de su naturaleza, a tal grado que se constituía en un territorio único e incomparable, perfectamente individualizado, distinto de España o de otros países europeos. En pocas palabras, era la valoración de lo propio y específico que configuraba ya las bases de una 'conciencia nacional', la misma que había logrado madurar, si bien lentamente en el pasado, de forma acelerada en el presente hasta alcanzar sólido arraigo en la élite civil e incluso religiosa.

\section{El escenario: fidelidad o ruptura con la Corona}

Constituye nudo gordiano de la crítica y estudio de los planteamientos y acciones políticas de los insurgentes en esta fase, los claros y expresos textos a favor del Rey, de la Iglesia, del origen divino de la monarquía, del acertado gobierno de las autoridades coloniales, del entendimiento entre criollos y chapetones; "conspiremos unánimemente con el único objeto de morir por Dios, Por el Rey y por la Patria. Esta es nuestra divisa"; ${ }^{14}$ todo lo cual contrasta con la naturaleza y vocación de unos Precursores de la ruptura con la madre patria.

En esta fase o período de lucha por la 'autonomía', parecería más bien que los ilustrados estaban convencidos de que vivían

14 Manifiesto de la Suprema Junta de Quito a la América, Doc. Cit. p. 76 bajo un gobierno progresista y que no perdían la fe en un monarca libre de prejuicios, capaz de comprender la asfixiante situación de la Audiencia y administrar las medidas convenientes para salir de tan dramática situación. En la primera y segunda etapas intelectuales de Espejo, por ejemplo, el Rey continuó siendo el "Verdadero padre de sus pueblos, a quien adornaban notables atributos: clemencia y laboriosidad..." Por 1785 Espejo creyó que el soberano, sus ministros y más autoridades, dechados de justicia, equilibrio y amor a los vasallos, recomendarían y pondrían en práctica sus sugerencias para preservar la salud de Quito y en 1787 aún confiaba que Un vasallo de un Rey católico, el más benigno que han conocido los siglos; un súbdito de V.E. Y cuyo pecado no es otro que haber querido ilustrar su Patria merecía esas gracias propias de una mano benigna. ${ }^{15}$ En otra obra señala: !Oh, cuánto el apacible y suavísimo gobierno del muy Ilustre Sr. Villalengua, retrata la dulcísima autoridad de nuestro augusto Monarca. ${ }^{16}$

Pero el escenario cambió radicalmente y de la noche a la mañana. A partir de su última prisión, 30 de enero de 1795, Espejo debió haber visto que los canales que él trató de abrir para la renovación de la Provincia se cerraban herméticamente uno tras otro. Los estrechos límites que imponía la cárcel a su acción debieron haber terminado destruyendo todo el optimismo ilustrado de los años anteriores y debieron haberle indicado que no había más salida o posibilidad que la subversión por el medio que fuese. Al menos su hermano Juan Pablo

\footnotetext{
${ }^{15}$ Ver, Pío Jaramillo Alvarado, “Apuntamiento para el estudio de la revolución del 10 de agosto de 1809”, Quito, en

Boletín del Archivo Nacional de Historia, $\mathrm{N}^{\circ} 94$, julio-diciembre, 1959.

${ }_{16}$ Ver, Carlos Paladines, Pensamiento Ilustrado Ecuatoriano, Quito, Corporación Editora Nacional y Banco Central del Ecuador, 1980, pp. 457-ss.
} 
fue claro en esto como se desprende de las inculpaciones que constan en el proceso judicial que se le siguió.

Para ese entonces la monarquía española había dado un vuelco de noventa grados bajo Carlos IV, quien desencadenó la reacción anti-ilustrada y tomó una serie de medidas para precautelar a sus colonias del contagio revolucionario: prohibición a los oficiales de que hablen de Francia, control de prensa, revisión de paquetes de correo, expulsión de individuos "dudosos", requisa de libros, cartas y otros documentos, etc. El endurecimiento se hizo aún mayor a partir de 1793 con la ejecución de Luis XVI y María Antonieta y sobre todo por la declaración de Guerra contra España hecha por la Convención. Con pesar Espejo debió haberse enterado que los hombres progresistas del gobierno de Carlos III tuvieron que pasar por la amargura del destierro o el exilio. Durante el último año que Espejo vivía en libertad, el prestigio del Rey y la Monarquía española se vino a tierra para gran parte de la población hispanoamericana, especialmente para ciertos círculos revolucionarios de México, Santa Fe, Audiencia de Quito y Lima.

Por otra parte, la renovación cultural propiciada a partir de 1779 había sido ya ahogada casi por completo. La Universidad de Quito había terminado convirtiéndose en aliada conservadora de la sociedad colonial quiteña, dedicada a presentar tesis filosóficas, teológicas y de derecho de carácter regalista. Además, estaba ya produciendo su fruto la larga campaña de rumores y acusaciones que desde 1787 hasta 1795 habían levantado los potentados de Chimborazo contra Espejo. Solo el proceso seguido por María Chiriboga contra Espejo exigió la declaración juramentada de aproximadamente unas treinta personas y los autos completos de este juicio que duró cerca de cinco años, reposan en más de ciento cincuenta folios. Presidente, alcaldes, regidores, capitanes, administradores, religiosos..., de Quito, Guayaquil, Chimborazo y hasta de Bogotá se vieron envueltos en el proceso. Un capcioso cuestionario, al que concurrieron a responder veinte y dos personas en la primera ocasión y luego seis, constituyó más que una guía para el interrogatorio, un claro documento de campaña para desprestigiarlo. Pocos procesos judiciales han alcanzado la relevancia de éste.

Por último, Primicias de la Cultura de Quito había cerrado ya sus ediciones sea por el escaso número de suscriptores, sea por la campaña de envilecimiento y crítica levantada contra el director y el diario, sea por la falta de materiales para publicar. Similar suerte había corrido la Sociedad de Amigos del País o Escuela de la Concordia.

$\mathrm{Si}$ a este reaccionario escenario de finales del S. XVIII lo confrontamos con una serie de actos revolucionarios que se desencadenaron por esos mismos años, será fácil colegir que existían sólidas razones a favor de la posible radicalización de la élite ilustrada. Valga como ejemplo, la denuncia presentada por fray Esteban Mosquera al Virrey de Santa Fe, en la que pedía "atienda cuán grande, cuán feroz y cuán firme debe ser la liga entre los que se hallan comprendidos en un delito tan grande y tan infame como el de la sublevación", de lo que se desprende que el movimiento independentista, claramente anti-monárquico, había tomado proporciones en el Virreinato de Santa Fe y en la provincia de Quito a finales del S. XVIII y primeros años del XIX. 
A todo esto habría que sumar la situación interna de bancarrota en que estaba sumida la Audiencia de Quito, especialmente la Sierra central y norte, por la inmisericorde succión de su riqueza realizada por los presidentes de la Audiencia y los cobradores de impuestos; ${ }^{17}$ por la inoperancia de sus autoridades para arbitrar las medidas que hubiesen permitido superar la crisis generalizada; por el decaimiento de sus minas, de la industria textil, de su comercio, de su agricultura,... En términos de Espejo la situación era de miseria generalizada.

\section{Los primeros pasos de constitución de un Estado moderno}

La construcción de los Estados a lo largo de la historia ha dependido de la conjugación de diversos factores, entre los que destacan: el territorio, la población, el sistema de gobierno, el sistema productivo,... factores estos y otros más que convergieron en las más diversas fórmulas políticas: monarquía, aristocracia y democracia; administración federal o unitaria; gobierno colectivo o de un solo

17 Los frutos de esta política no se hicieron esperar y esto explica que en una región tan empobrecida como la Audiencia de Quito de finales del siglo XVIII, el segundo Presidente nombrado por Carlos III, Don José García de León y Pizarro, en el lapso de cuatro años, 1778-1782, según comenta González Suárez, tuvo la satisfacción de remitir a Cartagena un millón, diez y siete mil trescientos cincuenta pesos, suma enorme, comparada con la que había enviado su predecesor: pues, en once años Diguja no alcanzó a enviar por el situado más que setecientos trece mil cincuenta y un pesos". Si al drenaje por vía de tributación del indígena añadimos otra serie de mecanismos de succión como la suma considerable que se enviaba a Cartagena y Santa María para sostener al ejército y los presidios -González Suárez habla de 41375 pesos anuales-, los impuestos llamados de temporalidades o gastos causados por la expulsión de los Jesuitas y para su sostenimiento en España, los graciosos donativos que el Rey Felipe V supo exigir y todas las imposiciones que las transacciones comerciales con Lima, la Nueva España, Nueva Granada,... exigían, el resultado final es el vaciamiento casi absoluto de las riquezas de Quito. Ver. Carlos Paladines (editor), Espejo Conciencia crítica de su época, Quito. Ediciones de la Universidad Católica del Ecuador, 1978, pp. 196 - ss. individuo; absolutismo, dictadura; reyes, príncipes, ciudadanos, etc. ${ }^{18}$ A estos componentes habría que sumar la lógica de organización o hilo conductor de los diversos factores y además los elementos propios, específicos de cada realidad o contexto.

Para el caso de conformación de un Estado moderno habrá que sumar otros elementos más: la separación de poderes; el régimen de derecho; la protección de la libertad y la igualdad aunque sea formal; las nuevas formas y relaciones de producción y comercio, etc. Algunos autores añaden la creación de una infraestructura administrativa, económica, financiera, militar y diplomática unificada; el establecimiento de un poder central suficientemente fuerte como para poder someter a las antiguas estructuras o poderes feudales, particularmente al poder de la iglesia y del naciente ejército que, en el caso ecuatoriano, tardaron varias décadas en controlarse. El Proyecto de Constitución para el Reino de Quito elaborado por Calixto Miranda, por ejemplo, era claro en cuanto a la declaratoria de independencia de España, mas no lo era en relación a la independencia del poder eclesiástico, características ésta última insoslayable le en un Estado moderno. Miranda dedicó especial atención más bien a la defensa del patronato eclesiástico y del gobierno de los religiosos.

La élite política e intelectual de la Audiencia de Quito para la conformación del Estado que debía reemplazar al colonial tomó en cuenta, con mayor o menor éxito, varios de los factores que el debate y la información en aquella época había puesto sobre el ta-

\footnotetext{
${ }^{18}$ Varios autores, Problemas de formación del Estado $y$ de la nación en Hispanoamérica, Bonn-Alemania, Edit. Inter - Nationes, 1984, p. 217.
} 
pete, en la mesa de discusión. El nuevo régimen propuesto se juzgó que debía descansar en pilares como la división de poderes, la elección de autoridades, igualdad de derechos, servicio público remunerado, etc. Se juzgó y se legisló, por ejemplo, sobre la justicia y la ineludible necesidad que de ella tenía el flamante Estado. Sin justicia y sin leyes cualquier forma de gobierno sería contraproducente; nada que merezca el nombre de república o Estado podía subsistir sin la administración de la justicia. De igual modo sin leyes no sería posible una sociedad más segura y más rica. Un Estado bien constituido en sus leyes y costumbres podía sobrevivir en un escenario que además de complejo era sumamente delicado, dada la pervivencia de fuerzas e instituciones favorables a la monarquía española. Menor dedicación se dio a las condiciones materiales en que hubo de nacer el nuevo Estado; un sistema productivo fraccionado en tres zonas económicas que no lograban integrarse, una de ella en aguda crisis y todas reacias al paso del sistema colonial hacia nuevas fuerzas y relaciones sociales de producción.

Veamos al detalle algunos de estos factores, elementos básicos del Estado moderno, con los cuales se pretendía esculpir el nuevo rostro de Quito y que establecían claras diferencias con el sistema feudal o colonial de ejercicio del poder. Para su justa valoración, sea del caso previamente recordar que el Estado moderno nació en Ecuador en un escenario de limitaciones y problemas de orden político y económico; en medio de grandes acontecimientos históricos: la crisis de la monarquía no solo española sino de Europa en general, la invasión napoleónica, la integración a la economía mundial de la América española y portuguesa, la independencia de Norteamérica,... mega o macro tendencias como se diría hoy en día, pero también en medio de circunstancias y demandas locales e inmediatas: a) La Sierra centro y norte atravesaba por una depresión económica que le duraba ya varias décadas sin lograr encontrar el producto o los negocios que pudiesen sacarla de su crisis; b) La población tanto del callejón interandino como de la Costa crecía lentamente y en la región amazónica era mínima (Ver Anexo No.1: Población del Ecuador: 1779/80--- 1857/58); c) Las guerras demandaron, por cerca de dos décadas, ingentes recursos para la alimentación de la tropa y para las remuneraciones tanto del ejército español como del independentista; d) Las exportaciones crecían lentamente (Ver Anexo No. 2: exportaciones de cacao 1700 1842); e) las élites nativas, los "criollos" no eran aún admitidos en el ámbito cultural y educativo y mucho menos en los aparatos de Estado.

\section{Pautas de las Constituciones quiteñas}

En medio de escenario tan complejo las fórmulas diseñadas e implementadas entre 1809-1830: la Carta Magna de 1809; la Constitución Quiteña de 1812, las Constituciones de la Gran Colombiana de 1821 y 1830, y la primera Constitución como República del Ecuador de 1830 constituyen el material constitucional que sirvió para la construcción del nuevo edificio. Se examinará sólo de algunas de estas Constituciones las pautas o categorías básicas, que permitieron ordenar los datos y facilitan la comprensión de lo que se intentaba crear: un Estado y una sociedad de caracteres modernos que debía conducir al país hacia la "tierra prometida". ${ }^{19}$

\footnotetext{
${ }^{19}$ Sobre el Movimiento Ilustrado Ecuatoriano me he ocupado en diversas oportunidades. Puede verse: Pensamiento lustrado Ecuatoriano (1980); El pensamiento pedagógico ilustrado (1997); El
} 
La praxis política de estos años encontró en estas categorías o pautas emblemáticas, trabajadas a lo largo de aproximadamente un siglo, las "luces" para el trajinar del poder en esas tormentosas décadas de inicio de la vida republicana. 'Soberanía reasumida', fidelidad o ruptura con la Corona, 'división de poderes', 'quiteñidad nación',... no solo eran temas de debate académico sino el material con el que había que levantar el nuevo edificio.

Sea suficiente examinar sumariamente algunas de estas categorías o pautas, no tanto en su acepción de normas que se debían seguir (sentido pasivo o formal), cuanto de pacto, acuerdo o compromiso entre diversos actores e intereses por implementar determinadas medidas que se juzgaba les favorecían (sentido activo o material). Las Constituciones antes que intentos de concretar un orden teorético, universal y a-histórico han de ser vistas como el programa o convenio que han acordado o pactado llevar a cabo determinados grupos, regiones o beneficiarios. Bajo esta segunda perspectiva, que supedita a la primera, las relaciones que se entretejen entre teoría y práctica son más ricas que la visión tradicional que privilegia más a la teoría en desmedro de la práctica e incluso desconoce el peso que la práctica tiene para la formulación y reformulación de la teoría. ${ }^{20}$

movimiento ilustrado y la Independencia de Quito (2009), obras en la que se desarrolla con mayor detenimiento los temas tratados en el presente artículo. 20 Véase, Arturo Roig, "Algunas pautas del pensamiento latinoamericano", en Arturo Roig, Metodología y Filosofía del Pensamiento latinoamericano, Quito, Ed. Academia Nacional de Historia, 2013, p.108.
Primera pauta: la delimitación del territorio del nuevo Estado

Tanto en la Carta Magna (1809) como en la Constitución Quiteña (1812), una de las primeras preocupaciones fue pactar con los dirigentes de diversas ciudades para poder delimitar con la mayor precisión y tino posibles el territorio del nuevo cuerpo político y sus límites, no tan claros dadas las aspiraciones de los vecinos y el haber dependido por décadas de los virreinatos de Lima y Santa Fe. En otras palabras no bien concluida la independencia de España, batalla que duró décadas, se tuvo que enfrentar la separación de nuestros vecinos. La Audiencia de Quito estuvo enclavada o dependiente del Virreinato de Lima y del de Santa Fe de Bogotá y las primeras décadas de vida como Estado soberano estuvieron marcadas por conflictos limítrofes con ellos. Sea suficiente recordar la invasión peruana de 1830 que en un primer momento resultó favorable al Ecuador con la batalla de Tarqui o el fallido intento de recuperar la provincia del Cauca de parte del presidente Flores que terminó con la incorporación a Colombia de las provincias de Pasto, Popayán y Buenaventura que mantenían una cálida y estrecha relación con la Audiencia de Quito. Flores perdió la guerra. Se celebró un Tratado de límites en la ciudad de Pasto, el 8 de diciembre de 1832, fijándose el río Carchi como frontera y dejando pendiente la decisión sobre los puertos de La Tola y Tumaco.

Así se transformó la demarcación de las fronteras en preocupación fundamental del nuevo Estado para afincar su soberanía sobre un territorio reconocido como propio. Inmediatamente se planteó el problema de cómo establecer dichas fronteras. Para establecer o para reclamar determinados límites se recurrió al pasado colonial, a la 
subdivisión de las antiguas Audiencias, pero también esta alternativa se mostró al final insuficiente. Ecuador, por ejemplo, reconocía como territorio propio el de la Real Audiencia de Quito, pero esta definición arrastraba dificultades de establecer fronteras hacia el este, es decir, hacia la Amazonia. Cordilleras, ríos y selvas tornaban difícil la penetración hacia el este y determinaron el aislamiento de vastas regiones así como el surgimiento de sociedades e intereses más locales que nacionales. Esta dificultad planteada ya en la época colonial, volvió a cobrar vida a inicios de la República y se prolongó hasta avanzado el S. XX.

Segunda pauta: la población de la capital y de las provincias

También hubo que convenir con la precisión y tino posibles los pueblos que integrarían la nueva circunscripción territorial. En los textos constitucionales se hace alusión a la población de la 'Capital' y de las 'Provincias': “Guayaquil, Popayán, Pasto, Barbacoas y Panamá, que ahora dependen de los virreinatos de Lima y Santa $\mathrm{Fe}$, las cuales se procurará atraer,..." En la capital se consideró a la población de los barrios del centro o catedral, San Sebastián, San Roque, Santa Bárbara y San Marcos. Es del caso resaltar que los 'representantes' de los barrios de la Capital "unidos con los representantes de los cabildos de las provincias sujetas actualmente a esta Gobernación y las que se unieren voluntariamente (...) compondrán una 'Junta Suprema' que gobernará interinamente".

La convergencia de territorio y población, espacio e historia, vecindad y ciudadanía, alimentó a los sentimientos de 'Quiteñidad', categoría de resonancia hasta el presente.
Sus antecedentes se pueden ubicar, por fijar una fecha, en 1791. Los jesuitas expulsados venían trabajando la traducción al italiano de la Historia del Reino de Quito, en la América Meridional de Juan de Velasco, nativo del mismo reino e iniciador de la historia nacional. En calidad de colofón se planeaba colocar el discurso que dirigiera Espejo a los quiteños para la erección de una sociedad patriótica. Se enlazaba así el proceso de autoconciencia y autovaloración afirmado por Juan de Velasco, heredero de los primeros cronistas y de las tradiciones y leyendas manantiales de nacionalidad, con la tarea de Espejo, de hondas repercusiones en sus discípulos, especialmente en Miguel A. Rodríguez, autor de la Constitución quiteña de 1812.

Los ilustrados, las misiones científicas, La Condamine, Humboldt, Maldonado,... colaboraron a la conformación de la conciencia histórica de los quiteños de múltiples maneras. La censura que se desarrolló en El Nuevo Luciano contra las letras españolas fue una forma de afianzamiento de la quiteñidad, pues el repudio al español por cuanto seguía negando al criollo, un lugar en las letras y en general en la cultura, implicaba el reconocimiento de su propia solvencia académica, y el abogar por que los estudiantes quiteños no partan hacia Salamanca sino que más bien se eduquen en Quito pretendía apuntalar uno de los pilares más seguros para lograr independencia intelectual de España: la valoración y estudio de lo propio.

La crítica que se desarrolló contra los prejuicios de los europeos hacia América, también constituye una toma de conciencia de sí y para sí y un situarse como valiosos frente a ellos: 
... desde tres siglos ha, no se contenta la Europa de llamarnos rústicos y feroces, montaraces e indolentes, estúpidos y negados a la cultura. ¿Qué os parece, señores, de este concepto? Centenares de esos hombres cultos no dudan repetirlo y estamparlo en sus escritos. Si un astrónomo sabio, como La Condamine, alaba los ingenios de vuestra nobleza criolla, como testigo instrumental de vuestras prendas mentales, no falta algún temerario extranjero que publique que se engañó y que juzgó preocupado de pasión al ilustre académico. Mr. Paw se atreve $a$ decir, que son los americanos incapaces de las ciencias... ${ }^{21}$

Años más tarde, en el Manifiesto de la Junta Suprema de Quito al Público, 10 de agosto de 1809 , el repudio a la minusvaloración de que se era objeto de parte de las autoridades españolas alcanzó tonos radicales. En los últimos tiempos, "no se ha visto otra cosa que un descuido vergonzoso, una apatía humillante y un desprecio criminal de los derechos sacrosantos que nos ha concedido la naturaleza. No se nos ha tenido por hombres, sino por bestias de carga, destinados a soportar el yugo que se quisiera imponer". ${ }^{22}$

Otra manifestación de la quiteñidad en cuanto valiosa son las constantes alusiones que se encuentran sobre la gloria quitense, gloria que el resto del mundo no se atreve todavía a creer pueda reposar en los quiteños: esto es, que haya sublimidad en vuestros genios, nobleza en vuestros talentos, sentimientos en vuestro corazón y heroicidad en vuestros pechos. Aspectos todos que convergían a conformar el orgullo nacional, segunda fuente de la pública felicidad.

\footnotetext{
${ }^{21}$ Eugenio Espejo, Primicias de la Cultura de Quito, Ecuador, Publicación del Archivo Municipal, 1947, pp. 41-42.

${ }^{22}$ I. Municipio de Quito, Rev. del Museo Histórico, No. 69,2010 , p. 70 .
}

Son célebres, igualmente las anotaciones sobre el arte quiteño y la habilidad de nuestros orfebres y artesanos. También se resalta las figuras sobresalientes de Pedro Vicente Maldonado, hombre respetado en Londres por sus observaciones históricogeográficas; del pintor Miguel de Santiago, del artista de la madera y el mármol, Caspicara; de Cortez, notable en la pintura sobre la tabla y el lienzo; de Mariano Villalobos, descubridor de la canela,...Es indiscutible la contribución de estos autores a una revaloración de nuestra riqueza nacional.

Pero no solo las cualidades del quiteño se rescatan, hasta el espacio físico es recobrado positivamente.

En este momento, me parece, señores, que tengo dentro de mis manos a todo el globo; y lo examino, yo lo revuelvo por todas partes, yo observo sus innumerables posiciones, y en todo él no encuentro horizonte más risueño, clima más benigno, campos más verdes $y$ fecundos, cielo más claro y sereno que el de Quito... ${ }^{23}$

Este reconocimiento y valoración de sí mismo tiene la más fácil comprobación en el título de varias de las obras de Espejo: El Nuevo Luciano de Quito, Primicias de la Cultura de Quito, Defensa de los Curas de Riobamba, Memorias sobre el corte de Quinas. Con el correr de los años este incipiente reconocimiento y valoración, envuelto aún en el sentimiento o en la exageración contribuyó a que los criollos reclamen el derecho a sus propias cosas, a su propia cultura y a formar Juntas para su propio gobierno.

En definitiva, en los pliegues de la dinámica de la quiteñidad tomaron cuerpo, luego de un largo proceso de gestación, los

\footnotetext{
${ }^{23}$ Eugenio Espejo, Primicias de la Cultura de Quito, ob. cit. p. 66 .
} 
sentimientos nacionales y de pertenencia que repercutirían no solo en la exigencia de diseñar y crear un 'Estado moderno' sino también en la delimitación y lucha por sus fronteras o límites y su población, expresión de su soberanía.

Pero la categoría de Quiteñidad también se vio sacudida como consecuencia de los procesos independentistas y de la derrota del ideal bolivariano de construir una gran nación latinoamericana unida, al fracasar esa vía en todos los nacientes Estados que se vieron compelidos a delimitar su identidad propia y particular en confrontación con sus colindantes. No fue suficiente ni el común origen pre-histórico, ni los elementos culturales, de idioma y religión de la fase colonial; ni el modelo político y administrativo de inicios de la vida republicana para detener los enfrentamientos. Por ello, a partir de los problemas limítrofes es que se puede hablar de un proceso de construcción de identidades estatales, identidades que, a partir de los conflictos de fronteras comienzan a ejercitar su soberanía sobre un territorio reconocido como propio. ${ }^{24}$

Tercera pauta: la designación de autoridades

A partir de la integración de los miembros de la Junta Suprema se procedió a elegir y otorgar categorías especiales a las autoridades: ministros o secretarios de Estado, individuos natos de la Junta Suprema, Secretario y Presidente. "La Junta como representativa al Monarca, tendrá el tratamiento de Majestad; el Presidente el

${ }^{24}$ Véase, Traverso Yépez, Martha, "La identidad nacional en Ecuador un acercamiento psicosocial a la construcción nacional". Tesis doctoral. Cit. http://eprints.ucm.es/tesis. de Alteza Serenísima, y sus vocales de Excelencia, menos el secretario particular a que se le dará el de Señoría".

¿Qué se escondía detrás de la Junta Supre$m a$, en otros textos denominada Junta Soberana, y del tratamiento 'real' que se debía dar a sus representantes? Se trataba de convenir en la supremacía, la máxima supremacía o soberanía de un cuerpo colegiado sobre todos sus componentes o individuos y asociaciones dentro del él, y la independencia jurídica del Estado de todo dominio político externo. Los constituyentes así lo entendieron al declarar solemnemente, en las primeras líneas de Constitución de la Junta Suprema Gubernativa, "haber cesado en sus funciones los magistrados actuales de esta capital y de sus provincias". Por encima de ella no cabía exista ningún poder que pudiese decidir en situaciones de necesidad o imponer norma alguna.

¿Qué había detrás del concepto de Soberanía reasumida? ¿Qué rupturas y aportes estaban en juego? A mediados de febrero de 1812, exactamente el día 15 suscribieron la llamada Constitución de Quito los más diversos actores: el Obispo, algunos marqueses y representantes del Cabildo, miembros del clero, de la nobleza, de las parroquias de Quito y de ciudades como Riobamba, Latacunga, Alausí, Guaranda y Ambato. Se enviaron notas solicitando sumarse a otras "Provincias vinculadas políticamente a este Cuerpo luego que hayan recobrado la libertad civil de que se hallan privadas" 25

\footnotetext{
${ }^{25}$ Ibíd., p. 14. El Proyecto fue redactado por el Dr. D. Miguel Antonio Rodríguez. Finalizó su estudio el 12 de febrero. Expedida en Quito por el Supremo Congreso Constituyente del Estado el 15 de febrero de 1812. Publicado por primera vez por el investigador Celiano Monge en 1913. Los otros dos proyectos
} 
Sabido es que en la teoría tradicional la soberanía descansaba en el Monarca. El texto constitucional tiene el mérito de construirse sobre bases nuevas: la teoría del Contrato Social, cuyo supuesto fundamental es considerar al ser social y a la voluntad general como si estuviese compuesta de voluntades individuales, como si se hubiese originado por unificación de los sujetos que libremente se decidieron y se obligaron por una especie de contrato a depositar en otro: el gobernante, parte de su libertad a fin de no perderla por completo en la lucha de los intereses individuales encontrados (Hobbes) o a fin de desarrollarla en mejor forma (Rousseau).

Una derivación importante de esta conocida teoría señala que todo poder de gobierno, ya sea encarnado en una persona o ejercido por una asamblea o mayoría, es siempre poder trasmitido o representado. La fuerza revolucionaria que implicaba esta nueva visión de las bases del Gobierno, no fue totalmente desarrollada en esta primera fase, pero sí es coherente asignar, por ejemplo, a Espejo, sus primeros brotes a través de diferentes reflexiones en las que la fidelidad al Rey tiene como medida ya no el derecho divino, tan celosamente resguardado por el absolutismo monárquico, sino más bien el 'derecho del pueblo', derechos que algunos pensadores defendieron como hontanar originario de autoridad, con capacidad de elegir nuevo Rey cuando por situaciones especiales esa autoridad retornara a su origen: el pueblo. Espejo, no vivió para cuando se produjo ese vacío de poder, pero varios de sus alumnos,

presentados fueron los de los doctores D. Calixto Miranda y Suárez, Canónigo Maestreescuela, y D. Manuel Guisado y Palazuelos, canónigo penitenciario. Se conoce el texto del elaborado por el doctor Miranda no así el del doctor Guisado. amigos y familiares sí tuvieron la suerte de participar en esa hora. ${ }^{26}$

La tesis de la Carta Magna de 1809 y de la Constitución quiteña de 1812 es que habiendo desaparecido la soberanía real por efecto de la invasión napoleónica, el poder y la soberanía volvía a radicarse en el pueblo, en quien originariamente residía tal potestad. Fue esa soberanía reasumida la que legitimó la expedición de la nueva Constitución y la fundación del Estado de Quito. "El Pueblo Soberano del Estado de Quito, legítimamente representado por los Diputados de las Provincias libres que lo forman". Líneas más abajo: "la Soberanía que originalmente reside en ellos".

Alcanzó este proceso su clímax en la fórmula del juramento que debían prestar los jefes de las corporaciones de la Capital, según consta en el Acta del Congreso del 11 de diciembre de 1811 y en la Constitución Quiteña del 15 de febrero de 1812. La fórmula es de por sí elocuente: "¿juran reconocer la legítima representación y autoridad de todas las provincias libres que actualmente constituyen el Reino de Quito, la cual reside en este Supremo Congreso que se halla instalado?". ${ }^{27}$

Así quedó atrás la obediencia al gobierno de Santa Fe, al Consejo de Regencia, a las

${ }^{26}$ Eugenio Espejo, El Nuevo Luciano de Quito, en Escritos de Espejo, t. I, pp. 295-6.

${ }^{27} \mathrm{La}$ fórmula completa del juramento que debían prestar los jefes de las corporaciones fue la siguiente: "juran reconocer la legítima representación y autoridad de todas las Provincias libres que actualmente constituyen el Reyno de Quito, la cual reside en el Supremo Congreso que se halla instalado? Prometen obedecer, sostener y auxiliar sus órdenes, providencias y Reglamentos que en todos los ramos del Gobierno se acuerden y establezcan para el mejor desempeño de sus funciones y dirección de todos los negocios públicos, en obsequio de la Religión, el Rey y la Patria?”, Borrero González, Manuel María, La revolución quiteña 1809 1812,1962 , pp. 329-340 
Cortes congregadas extraordinariamente en la isla de León y aún a la misma monarquía, al momento acéfala, y se planteaba un nuevo lugar de asiento o fundamento de la soberanía y se ensayaban los primeros pasos de vida republicana y de construcción del Estado moderno en el Ecuador. Muchos de los que prestaron juramento fueron penados años más tarde con la confiscación de sus bienes, el destierro, la cárcel y hasta su asesinato.

Quinta pauta: la organización del poder vía 'división de poderes'

Los textos constitucionales del año 1809 también establecen en la práctica, aunque no de modo formal, este pilar fundamental del Estado moderno, que solo tres años después, en la Constitución de 1812, alcanzó detallada formulación. Los documentos del año 1809 pusieron en marcha la división de poderes en el Estado desde su primer día de constitución, al establecer un ejecutivo, asumido por el marqués de Selva Alegre; un legislativo, asumido por la Junta Suprema, y un poder judicial asumido por las salas de lo Civil y de lo Criminal, con sus respectivos integrantes, La Constitución quiteña coronó esta estructura al establecer en la sección segunda lo referente al poder Ejecutivo, Arts. 22-33; en la tercera lo relativo al poder Legislativo, Arts. 34-44, y en la cuarta el poder Judicial, Arts. 45-54. La primera sección está dedicada a los problemas de representatividad del Estado de Quito como de sus órganos de gobierno, Arts. 1-21. La representatividad del Congreso de Diputados fue desarrollada en forma exhaustiva desde el Art. 7 al 19. No se hizo constar restricciones a este derecho, ellas vinieron años después, en la Constitución de 1830, Arts. 12 y 13. Para mayor esclarecimiento se adjunta un cuadro comparativo con la Constitución norteamericana y la de Cádiz. Llama la atención tanto la similitud con la Constitución norteamericana como las marcadas diferencias con la de Cádiz. ${ }^{28}$ (Ver Anexo No. 3: Estructura Constituciones).

Décadas después Juan Montalvo valorará esta mediación a su criterio capital:

En una buena democracia los poderes han de estar bien distribuidos; el legislativo, el ejecutivo y el judicial, rueda cada uno en su órbita respectiva, sus jurisdicciones se tocan, pero jamás se confunden: si el uno quiere conquistar algo, si pone el pie en el territorio de los otros, piérdese el equilibrio, tambalea la máquina, se desquicia y cae desbaratada.(...)El poder ejecutivo tiene por ellas mismas - las leyes- facultades exorbitantes, y cuando no las tiene, se las arroga de mano poderosa. La violación de una ley es un paso a la tiranía". "Los tres poderes que constituyen el gobierno van a dar todos a un hombre en el despotismo: el príncipe es legislador, ejecutor de leyes, administrador de la justicia. En esta forma de gobierno el equilibrio de los poderes no tiene cabida. $^{29}$

Entre las ventajas que traía consigo esta nueva forma de organización del poder, cabe resaltar las siguientes, en contraste con las formas de gobierno vigentes por más de 300 años. Se crearon diferentes

\footnotetext{
${ }^{28}$ Para un análisis más detallado me permito remitir a Ekkehart Keeding, Surge la nación, La Ilustración en la Audiencia de Quito. Quito, Banco Central del Ecuador, 2008. Se señala, en el acápite: "Índice de nombres propios y de materias: Estados Unidos de Norteamérica", con mayores detalles el influjo del proceso independentista norteamericano en autores de la Audiencia de Quito. También puede verse, Carlos Paladines: "Ilustración francesa e ilustración ecuatoriana", en Nación, Estado y Conciencia Nacional, Ecuador, Corporación Editora Nacional, 1992, pp.53-ss.

29 Juan Montalvo El Cosmopolita, T.I, ob. cit. pp. 381 y 382. El Regenerador, T. I. p.149.
} 
órganos autónomos al interior del cuerpo del Estado, cuyos dictámenes o decisiones no debían ser invalidados, modificados o anulados por otro órgano. El poder debía estar institucionalizado y no personalizado; vale decir, debía recaer en instituciones jurídico-políticas y no en personas específicas. Tal vez el requisito más importante tenía que ver con que, tanto las normas jurídicas como las actuaciones de sus autoridades al aplicarlas, debían respetar, promover y consagrar los derechos esenciales que emanan de la naturaleza de las personas y de los cuerpos intermedios que constituyen la trama de la sociedad.

Sexta pauta: la construcción de la República

Iniciada la vida independiente de España se impuso la urgencia por organizar el Estado, ${ }^{30}$ a partir de una optimista visión de los momentos de esplendor de la República romana, cuando los ciudadanos participaban y deliberaban sobre las necesidades de la comunidad, los derechos de las personas y eran capaces incluso de sacrificar su propio interés cuando el bien de la comunidad lo demandaba. Seguramente fue Bolívar quien mejor representó esta posición e insistió no solo

\footnotetext{
${ }^{30}$ Constan en la Biblioteca Nacional Eugenio Espejo y en otras bibliotecas de Quito, numerosas ediciones de las obras de Marco Tulio Cicerón y del Tratado de la República correspondientes a 1565-1723-1729-17431744-1746-1751 y 1756. En los últimos años una nueva vertiente de interpretación confirma el enfoque asumido. Ver, Miguel Malagón Pinzón, “El pensamiento republicano de Bolívar en el proyecto constitucional de Angostura de 1819 y en la constitución boliviana de 1826", en Rev. de Derecho, $N^{o}$ 27, Universidad del Norte, Barranquilla, 2007: "Nada más alejado de la realidad. Nosotros tenemos otros argumentos que nos llevan a plantear que la ideología de Simón Bolívar perteneció al pensamiento republicano, y no a las ideas liberales. Republicanismo que se origina en Roma, que será exaltado por Maquiavelo y que tendrá en Rousseau y en Robespierre a algunos de sus más grandes representantes", p. 102
}

en la necesidad de romper con la Madre Patria, esa "desnaturalizada madrastra" de quien todo lo sufrimos, sino también en la urgencia de establecer un sistema de gobierno que como en tiempos de la Roma imperial fuese capaz de instaurar los mayores beneficios: "La Constitución romana es la que mayor poder y fortuna, ha producido a ningún pueblo del mundo". (...) Roma y Gran Bretaña son las naciones que más han sobresalido entre las antiguas y modernas; ambas nacieron para mandar $y$ ser libres; pero ambas se constituyeron no con brillantes formas de libertad, sino con establecimientos sólidos". ${ }_{-}^{31}$

La optimista y tal vez hasta idílica visión de la vida republicana en los tiempos de Grecia, Roma e Inglaterra que presentara Bolívar en su ya inmortal Discurso Inaugural del Congreso de Angostura, 1819; en la propuesta de Constitución Boliviana de 1826, e incluso en la Carta de Jamaica, 1815, cuando aún era difícil presentir la suerte futura del Nuevo Mundo, da muestras de la unción con que el Libertador abordaba el tema de la conformación de las Repúblicas, a partir del requerimiento de ihombres virtuosos, hombres patriotas, hombres ilustrados para la constitución de las Repúblicas! ${ }^{32}$ Las virtudes cívicas, la ciudadanía, eran la más poderosa arma para institucionalizar todas las promesas de libertad y respeto a los derechos humanos, por una parte; $y$, por otra, para arrinconar a las ambiciones de poder y riqueza, visión comprensible en una persona que dedicó

\footnotetext{
31 Simón Bolívar, Discurso de Angostura, México, Universidad Autónoma de México, Cuadernos de Cultura Latinoamericana, 1978, pp.18 y 19.

${ }^{32}$ Simón Bolívar, Carta de Jamaica, Contestación de un americano meridional a un caballero de esta isla (Henry Cullen), Kingston 1815, México, Universidad Autónoma de México, Cuadernos de Cultura Latinoamericana, 1978, p. 17. Discurso de Angostura, p. 17.
} 
toda su fortuna, una de las más grandes de Venezuela, al proceso independentista

En el centro de esta optimista visión estaba: por una parte, la reacción a la ineficiencia extrema y a la corrupción generalizada de que dieron muestra las autoridades coloniales en las últimas décadas; $y$, por otra, la esperanza de que las nuevas autoridades iban a administrar la riqueza en forma diferente, con claras muestras de probidad, conocimiento $y$ defensa del bien común. Se partía del supuesto de que las nuevas autoridades serían gobernantes con acendrada ética pública y no responderían a intereses particulares y una vez bajo el control del Estado redistribuirían equitativamente los bienes y no para su propio beneficio.

Tan optimista esperanza consideraba a la "corrupción" como problema de personas o individuos con mayor o menor carga moral. No se supo superar a la teoría dieciochesca de la corrupción, cerrando así las puertas a una compresión más institucional y profunda. La propia autocrítica quedó de este modo excluida y el discurso se dirigió solo a la denuncia a los individuos más que a los grupos o clases que ejercían por su misma dinámica y sobrevivencia la defensa de sus intereses e incluso de estructuras de dominación. Los actores políticos fueron vistos más en sus cualidades que en sus limitaciones estructurales.

\section{Séptima pauta: los sagrados derechos de la naturaleza humana}

La declaración inicial de la Constitución de Quito alude en el texto introductorio: Preámbulo, en dos ocasiones a los derechos humanos: al tratar sobre la naturaleza de los hombres y al tratar sobre los fines del Estado. Sobre lo primero dice: "en uso de los imprescindibles derechos que Dios mismo como autor de la naturaleza ha concedido a los hombres para conservar su libertad, y proveer cuanto sea conveniente a la seguridad y prosperidad de todos, y de cada uno en particular". Sobre lo segundo señala: "persuadido (El Pueblo Soberano de Quito), a que el fin de toda asociación política es la conservación de los sagrados derechos del hombre por medio del establecimiento de una autoridad política, que lo dirija, y gobierne, de un tesoro común que lo sostenga, y de unas fuerzas Armadas que lo defiendan, (...) sanciona los artículos siguientes que formarán en lo sucesivo la Constitución de este Estado". (Las palabras en negrilla me corresponden)

Al momento, valga resaltar que se trata de una excelente descripción o síntesis sobre los fines a los que debe orientarse una organización política. El Estado quiteño queda definido por la idea de que él se justifica solamente si sirve para "...conservar los sagrados derechos del hombre, conservar su la libertad y proveer cuanto sea conveniente a la seguridad y prosperidad de todos y de cada uno en particular". Queda así señalada la libertad y la felicidad como el horizonte final.

También en este caso las raíces hay ubicar décadas antes. Por 1779 , en su primera obra: El Nuevo Luciano de Quito, a propósito de la poesía, Espejo, expuso su concepto sobre 'naturaleza', 'conocimiento natural' y 'razón natural'. ${ }^{33}$ Este dato un tanto insignificante a primera vista, tiene trascendencia. Para la llustración por naturaleza y conocimiento natural no se debía entender el conocer referente tan solo al ámbito del puro ser físico o biológico, en oposición al conocer de las realidades de carácter humanista o

\footnotetext{
${ }^{33}$ Ibíd., pp. 210-ss.
} 
espiritual, sino más bien un origen, una estructura básica o fundamento de verdad. Para los ilustrados era 'natural' toda realidad tanto física como espiritual, terrenal o celestial, subjetiva u objetiva, interna o externa, pero siempre y cuando fuese capaz de fundar de manera inmanente la razón de ser o explicación de algo desde sí misma; es decir, de descansar sobre sí misma y tener dentro de sí su centro de gravedad y su propia luminosidad; o en otros términos, explicarse en forma independiente de cualquier recurso a revelaciones trascendentes o místicas. La ciencia ilustrada se niega a reconocer como principio de coherencia o explicación de una realidad lo supra histórico, lo mágico o mítico, lo sobrenatural.

Con el tiempo Espejo, a propósito de Voltaire defendió lo acertado de su concepción sobre el estilo natural, mérito que no se debe negar o arrebatar a una persona por las deficiencias o errores en que pudiese haber caído en otros campos:

Ama la naturalidad, la fluidez y una pureza de estilo persa y varonil. $Y$ en todas estas partes hacen justicia a su mérito, todos o casi todos los franceses de su tiempo, y aún los extraños, que tienen voto en la materia. Lo que abominan y detestan con razón es su irreligión, su mala fe y su espíritu filosófico, de que el infeliz se jactaba con tanta vanidad y presunción. Desgracia ha sido que dos ingenios tan sobresalientes para la poesía francesa, como Voltaire y Rousseau, tuviesen el corazón tan apestado y corrompido en la divina ciencia de la Religión. ${ }^{34}$

Esta clara separación de fronteras que se concede, al menos en el círculo ilustrado, por 1779 a la poesía y a la religión, pero que años

${ }^{34}$ Ibíd., p. 210. después se hizo extensivo a otros campos como el de la economía, la física y las ciencias de la naturaleza en general, es lo que permitió a los ilustrados construir también la órbita política a partir de sí misma, sin necesidad de derivarla de una potestad divina, inaccesible e impenetrable a la razón humana; reflexión que constituyó un paso revolucionario, en ese entonces, de enormes consecuencias. Espejo al haber sentado las bases del 'conocer natural' dejó la simiente de una concepción renovada, que si bien él no avanzó sino en uno que otro texto a aplicar al mundo político, sin embargo no merma su mérito.

Refiriéndose a la independencia que debía guardar la ciencia de la religión, en 1785 afirmó:

Síguese ahora los oficios del ciudadano como físico. Antes de todo es preciso que el pueblo esté bien persuadido por éste, que las Viruelas son una epidemia pestilente. Esta sugestión era ociosa en Europa en donde están persuadidas generalmente las gentes, que no se contraen sino por contagio. Acá las muestras parece que están en la persuasión de que es un azote del cielo, que envía a la tierra Dios en el tiempo de su indignación. Por lo mismo, haciéndose fatalistas en línea de un conocimiento físico, creen que no le pueden evitar por la fuga, y que es preciso contraerlo o padecerlo como la infección del pecado original; impresión perniciosa que las vuelve indóciles a tomar los medios de preservarse propuestos en la Disertación. ${ }^{35}$

A partir de Espejo, el hecho de que el detentador máximo del poder, el Monarca, no esté sometido a ninguna limitación o condición, más que al juicio o disposición divina, no tendría ya sentido, por existir una

\footnotetext{
${ }^{35}$ Ibíd., p. 211.
} 
norma de carácter natural, unos principios o leyes a los cuales él también tenía que someterse. Esta exigencia ilustrada porque se mantengan normas fundamentales, inmutables y universales o porque se descubran a través de la ciencia las leyes que rigen determinadas esferas de la realidad, invalida por sus bases a la monarquía absoluta y la somete a nuevos principios de control, y en esta tarea de invalidación tuvo mucho que ver Espejo; quien por 1794 dijo:

Dios mismo es Todopoderoso y de infinita libertad en el bien, es limitado y de ninguna aptitud para el mal y el vicio. Sigue indefectiblemente el orden que desde antes de los siglos estableció su Providencia; sus leyes son inmutables, y Dios se sujeta a sus decretos eternos. Luego, los reyes están ligados inviolablemente a la ley indescriptible de la justicia; luego, los pueblos están sujetos a la cadena indisoluble del orden público y de los estatutos fundamentales de la sociedad. $^{36}$

El hecho de que Espejo adhiera a los planteamientos que sobre Derecho Natural realizaba Groccio y Puffendorf, éste último citado por Espejo, invalidaba el Absolutismo monárquico que sacrificaba a la vanidad de un solo individuo millares de infelices vasallos, pero no se ha de interpretar esta ruptura como el establecimiento de un abismo entre la religión y el derecho.

Además, Espejo al igual que Quiroga, Quiñones y Cienfuegos, Miguel Antonio Rodríguez eran personas versadas en las fuentes francesas y españolas últimas y son múltiples sus referencias a Rousseau, Montesquieu, Feijoo, por citar algunos. Tampoco faltan en algunos de ellos: Calama, Quijano, Quiroga, Rodríguez de

\footnotetext{
${ }^{36}$ Ibídem.
}

Soto, Montúfar, Juan Larrea referencias a las luchas independentistas de los Estados Unidos de Norteamérica. Quijano incluso reconoció el influjo de la Declaración de Independencia de Norteamérica, del 4 de julio de 1776 o de la Constitución de los Estados Unidos de 1787, en los patriotas integrantes de la primera y segunda juntas de Quito, de 1809 y 1810 hasta 1812.

El hecho de que Espejo juzgue que Dios y cada una de las obras de su creación, en este caso la monarquía, se regían por determinadas e inmutables leyes, nos avoca a la tarea de averiguar cuáles eran para él esas fuerzas o estatutos fundamentales de una sociedad, pues caben diferentes interpretaciones del problema. La teoría tradicional ubicaba como estatuto fundamental de una sociedad y más en concreto, de la autoridad, el origen divino de la misma. En Espejo mismo se encuentran textos a favor de esta interpretación:

Y veis aquí, Señores, como la economía de mi discurso me conduce sin violencia a manifestaciones que nuestros augustos soberanos, esas imágenes vivas de la divinidad, esos dioses sagrados de dos orbes, son los verdaderos grandes del mundo y del imperio, los monarcas, de verdad católicos, cristianísimos, porque ellos, subordinados en todo a las órdenes del Padre de los reyes y de su eterna Providencia, conocieron que fueron establecidos por protectores de la Iglesia y para conquistadores de estos climas tan vastos como remotos. ${ }^{37}$

Pero como hemos indicado, junto a esta clase de reflexiones coexisten otras de carácter renovador. El texto fundamental corresponde al año de 1785, época en la que el afán renovador estaba en ascenso y no se había

\footnotetext{
${ }^{37}$ Carlos Paladines, Espejo conciencia crítica de su época, ob. cit. p. 212.
} 
sufrido aún la arremetida de las fuerzas retardatarias. Dice Espejo argumentando a favor de la obligación que tienen los súbditos a obedecer y acatar las órdenes de un Rey:

Cuando no consideramos más de que por una necesidad inevitable de solicitarnos las ventajas de la sociedad, hemos radicado el depósito de la Autoridad Pública en el Rey; que por la misma razón le hemos entregado voluntariamente parte de nuestra libertad, para que haga de nosotros lo que juzgue conveniente; que su poder, en atención a este sacrificio, se extiende únicamente a procurar el bien común de sus vasallos; y que bajo de estas miras, no podemos resistir a sus preceptos, considerando bien que ellos no tienen otro objeto, que el del buen orden, la economía, la conservación y la felicidad del Estado. $^{38}$

Por el tratamiento que los primeros documentos aún otorgan a Fernando VII y al Consejo de Regencia, por la fuente y origen del derecho político de carácter aún ambiguo que consignan, como también por la ligazón a España que reconfirman, podrían pensarse que no se está, en estos documentos, frente a un proceso revolucionario sino más bien a un claro sometimiento a la organización monárquica de la península. Esto ha dado pie a que algunos historiadores pretendan justificar las exageradas alabanzas al Rey y al acendrado realismo de estos documentos, como una concesión que demandaba el tino o habilidad política, o como la necesidad de contemporizar con la nobleza local no del todo radicalizada.

Fue más bien la evolución del proceso mismo lo que fue aquilatando la posición de los próceres y del pueblo quiteño, y la

${ }^{38}$ Ibíd., p.213. sagacidad de sus dirigentes consistió en captar la crítica coyuntura que atravesaba la monarquía: su desprestigio, división y entrega a manos de Napoleón y José Bonaparte, para, sirviéndose de todo ello, como de punto de partida, ir radicalizando las concepciones políticas vigentes. Tampoco se puede olvidar que la masacre del 2 de agosto de 1810 terminó por echar al suelo el escaso prestigio que aún le quedaba a la monarquía y a sus representantes ante la población quiteña y especialmente frente a los círculos ilustrados que sufrieron en carne propia la ingenuidad de confiar en la palabra empeñada por el máximo representante real en la Audiencia, conde Ruiz de Castilla.

\section{Octava pauta: el Estado de Derecho}

Desde el punto de vista estrictamente jurídico, dos son las notas características del Estado de derecho: a saber, la sujeción de los poderes públicos -autoridades-y de los ciudadanos al ordenamiento constitucional y la defensa, protección y respeto a los derechos humanos que el mismo Estado está llamado a cumplir. Aunque parezca contradictorio el poder soberano del Estado queda subordinado al orden jurídico, se rige por un sistema de leyes e instituciones diseñadas y ordenadas por la Constitución.

En aquella época el Estado de derecho se valoraba en clara oposición al Estado monárquico, toda vez que frente al poder absoluto del monarca y de sus representantes en la Audiencia de Quito el ciudadano estaba inerme y por eso era fácil víctima del atropello y el autoritarismo. Baste recordar los diversos e infundados juicios y órdenes de prisión de que fue víctima el precursor de la Independencia del país. Lo novedoso fue que los derechos naturales -adquiridos por el mero hecho de nacer según la teoría 
ius-naturalista o la perspectiva religiosa o la secular, o por la mera constitución de la sociedad según la teoría contractualista- se transformaron en 'derechos civiles', asumidos por el nuevo Estado y con obligación de respetarlos y promoverlos.

Pero a pocos años de iniciado el sueño republicano de vivir bajo un Estado de derecho, en la Audiencia de Quito-Ecuador afloraron las dificultades y tensiones propias de tamaña empresa. Algunos conductores del momento, por ejemplo Rocafuerte, al no poder concretar buena parte de sus sueños e ilusiones intentaron obligar a sangre $y$ fuego a seguir el camino trazado. Cuestiones básicas como la tolerancia religiosa, la moralidad pública, el respeto a las leyes, el patriotismo, bases de la conducta ciudadana, no llegaron a convertirse en diques capaces de contener el desborde de las ambiciones, la corrupción y las luchas intestinas que caracterizaron nuestros primeros años de vida republicana.

Por otra parte, el Estado de derecho en "sentido formal" y el Estado de Derecho en "sentido material" ni en esa época ni en el presente han sabido coincidir y en buena medida terminó en letra muerta al no crearse las condiciones de posibilidad de su florecimiento. Con justa razón ya en los días de la Independencia se pintaron grafitis que con escepticismo aludían al hecho de que no se trataba más que del "último día de despotismo y el primero de lo mismo" o aquel que hacía alusión a que "la ley no se ha hecho más que para los de poncho".

Además, en las tres primeras décadas de vida republicana: 1830-1860 no faltaron los sobresaltos, los levantamientos militares y asonadas que no permitían integrar los intereses ni regionales ni provinciales o de grupos en un proyecto común. Se propagaron las insurrecciones, saqueos y golpes de cuartel a lo largo de toda la Gran Colombia y así se empeoró aún más la magra situación económica heredada de la Colonia, agravada por los gastos y destrucción ocasionados por las guerras de independencia. Hombres, acémilas, bastimentos, provisiones, vituallas y dinero habían sido tomados a las buenas o a las malas por los bandos contendientes, en un primer momento el ejército realista y el independentista, posteriormente por regimientos y destacamentos que se alineaban a favor o en contra de los caudillos militares y generales de turno. Los recursos no eran suficientes para nadie y el escenario no podía ser más explosivo.

El historiador Salvador Lara ha descrito este ambiente de inestabilidad, en estos términos:

El 12 de abril de 1823 , se dio un primer motín en Quito bajo el gobierno del General Salom, por una leva forzosa de reclutamiento en la plaza de Santo Domingo, debiendo lamentarse entonces 36 muertos y decenas de heridos. El 25 de mayo del siguiente año hubo un alzamiento realista en Gualaceo, sofocado a la fuerza. A mediados de 1826 se sublevó en Quito un cuerpo de veteranos, que fue sometido por el Gral. Flores, a la sazón Comandante General. Otro cuartelazo hubo en enero de 1827. Y en marzo de ese año, la III División Auxiliar Colombiana se sublevó en Lima: uno de sus contingentes llegó al Ecuador, haciéndose fuerte en Guayaquil, mientras Flores encabezaba en Cuenca la contrarrevolución: hubo varios combates y al fin se restableció el orden. ${ }^{39}$

En los dos primeros años de la presidencia de Juan José Flores la situación fue similar.

\footnotetext{
${ }^{39}$ Jorge Salvador Lara, "La república del Ecuador y el Gral. Juan José Flores". en Correspondencia del Libertador con el Gral. Juan José Flores, 1825-1830, Quito, Edit. Banco Central del Ecuador, 1977, pp.1718.
} 
De 1830 a 1832 estallaron tres graves revoluciones que desangraron al país. Y en 1833 y 1834 el Ecuador se convulsionó con una verdadera y prolongada guerra civil. El primer levantamiento ocurrió en nombre de Bolívar: lo encabezó el Gral. Luis Urdaneta (...) y logró sublevar contra Flores, acusándole de traición al Libertador, nada menos que a los generales Illingworth y Wright y al Crnel. Lecumberri, posteriormente se les unió el Crnel. Stagg. Samborondón, primero, y luego Cuenca y Loja se unieron al golpe. (...) En octubre de 1831 se sublevó el Batallón "Vargas", veterano de la independencia cubierto de gloria en Ayacucho. En agosto del 32 se sublevó en Latacunga el Batallón Flores, antes Girardot, también veterano de la independencia, por las mismas causas por las que se sublevó el Vargas: notable retraso en los pagos. Los revoltosos fusilaron a varios oficiales, saquearon Latacunga $y$ obligaron a pagar rescate. Luego avanzaron hacia Ambato, que también saquearon; siguieron hacia San Miguel de Chimbo, avanzaron hacia Daule, rumbo a Guayaquil, pero al saber que el puerto se aprestaba a resistirle, pasaron a Manabí. De 538 hombres que iniciaron el golpe, quedaron solo 14 , y de sus mujeres que les habían acompañado, solo $12 .{ }^{40}$

En los primeros años del gobierno de Rocafuerte no amainaron los levantamientos, lo cual condujo al Presidente a reclamar medidas drásticas: 'despotismo ilustrado' para contener el desborde de los intereses individuales, las pasiones e incluso la corrupción.

Desengañémonos, decía, las instituciones nuestras no son propicias a la paz y desarrollo de la prosperidad pública. Ellas suponen luces, virtudes y verdaderos principios de honor y de moral que no existen entre nosotros ni existirán dentro de cien años. Para contener tantos leguleyos ignorantes y revoltosos, tantos clérigos fanáticos y avarientos, y tantos mercachifles agiotistas es precisa la ley del alfanje; sólo el

${ }^{40}$ Ibíd., p. 41. temor puede sofocar el espíritu de anarquía, que parece estar entretejido en las fibras de nuestra organización social. De día en día me persuado más de la importancia de dar al Ejecutivo una energía que raye en benéfico despotismo, ese es el único modo de fijar la tranquilidad pública, y de sacar este país de la postración en que se halla, para ponerlo en el sendero de la civilización. A mí no me arredra el título de tirano, lo que me horroriza es la cruel idea de que por falta de valor y firmeza en el Gobierno, diez o doce anarquistas trastornen el orden, e interrumpan el curso pacífico de nuestra prosperidad (...) se necesita aquí mucha fuerza, y un rigor que toque en crueldad para sofocar el espíritu anárquico, que atormenta esta sociedad. A desesperados males, desesperados remedios, y yo me he propuesto conservar a todo trance la tranquilidad pública, y sólo revestido de una firmeza que inspire terror, podré conseguir tan importante objeto. (...) Palo y más palo es el único modo de gobernar esos países, plagados de inmoralidad, de vicios y de toda lepra social. $^{41}$

Los hombres ilustrados dispuestos a ayudar, incluso a riesgo de su propio bienestar, no fueron la mayoría y en su esfuerzo por viabilizar e institucionalizar los ideales ciudadanos y republicanos deslizaron sus planteamientos paulatinamente a postular medidas drásticas, ya que sin ellas no era factible anclar las aspiraciones colectivas, cumplir con las promesas ofrecidas y menos aún "cerrar el cráter de la revolución y fijar la paz bajo los auspicios de la libertad". Así nació un "despotismo" que desde arriba trató de imponer las fórmulas soñadas.

\section{Novena pauta: la libertad}

El tema de la libertad ocupó lugar central, en la teoría y en la práctica, en aquellos tiempos y fue en este nivel, al parecer el más

41 Citado por Kent Mecum, Vicente Rocafuerte el Prócer Andante, Guayaquil, Edit. Banco Central del Ecuador, 1983, pp. 176, 174. 
abstracto del pensamiento ilustrado, donde éste se tornó a su vez más concreto al poner al desnudo cómo esta categoría estaba ligada a la existencia y a la vida cotidiana, a la ruptura con la Madre patria que coartaba la libertad al comercio libre, a las exportaciones e importaciones,...

Seguramente los mayores avances en este ámbito realizó José Mejía Lequerica, 17751813, en la Corte de Cádiz. En España él desarrolló una dimensión o perspectiva especial del derecho a la libertad, derecho concebido como de nivel fundacional y centro o soporte de otros derechos. Con la Revolución Francesa, el pensamiento moderno, para algunos "pensamiento burgués", organiza a través del derecho a la libertad, entendido este como fundamento de todos los derechos, un conjunto de libertades como la libertad de expresión, de imprenta, de reunión, de conciencia, mercado, culto, compra-venta, contratación, etc. Más aún, plantea que la Sociedad y el Estado -mediante el Ilamado Pacto Social- se constituyen precisamente para garantizar todas estas libertades. ${ }^{42} \mathrm{EI}$ valor de cambio de los bienes y su proceso de intercambio se manifestó como factible solo entre individuos iguales y libres, al menos formalmente, y entre propietarios que tenían la libre disposición de sus bienes en forma ilimitada e incluso reclamaban libertad para el endeudamiento y la inversión extranjera, básicamente inglesa. Junto a la libertad política también estaba de por medio la libertad económica y comercial.

Además, Mejía fue quien con mayor agudeza desarrolló otros conceptos pilares de la modernidad: soberanía o autonomía,

${ }^{42}$ Véase, la Declaración de los Derechos del Hombre y del Ciudadano de la Revolución Francesa y la Declaración de Independencia de los Estados Unidos. separación de poderes, representación paritaria, igualdad ciudadana, libertad de imprenta, de pensamiento y de expresión, libertad de industria, derecho de propiedad, abolición de los señoríos, supresión de la Inquisición, etc.

También, en nadie mejor que en él se reflejaban los ideales enciclopedistas de aquellos tiempos. Mejía logró atesorar todos los títulos académicos posibles: en 1792 alcanzó el bachillerato en artes y en 1794 el grado de maestro en filosofía; en junio de 1798 rindió las pruebas de grado correspondientes a la licenciatura en teología; en mayo de 1803 obtuvo el título de licenciado y abogado en derecho; en marzo de 1805, con una tesis de botánica, el grado de bachiller en medicina. En 1796, por concurso, obtuvo la cátedra de gramática; posteriormente el cargo de catedrático de filosofía, y en los últimos años de su permanencia en Quito dictó la cátedra de ciencias naturales, cátedra que por vez primera constó en el pénsum de la universidad.

Mejía además mantuvo relación con los principales actores políticos que años más tarde serían los precursores y próceres de la Independencia de Quito. Él contrajo matrimonio con la hermana del precursor: Manuela de Santa Cruz y Espejo, siendo padrinos de dicha ceremonia Juan de Dios Morales y Josefa Tinajero y uno de los testigos Antonio Ante, personalidades que diez años después integraron la primera Junta Soberana: Morales en calidad de Secretario del Interior y Ante como encargado de comunicar al Presidente de la Real Audiencia la decisión que se había 
adoptado. Ambos cayeron en la masacre el 2 de agosto. ${ }^{43}$

Asimismo, desarrolló y defendió en Cádiz a partir del derecho a la libertad y a la igualdad el concepto de 'representatividad' que fue uno de los más característicos de la filosofía política ilustrada de comienzos del siglo XIX. De allí su insistencia por aclarar los mecanismos conducentes al ejercicio auténtico de la representación y regular y reclamar la representación paritaria de las provincias de ultramar ante las Cortes.

El debate sobre la representatividad también implicaba la defensa del legislativo, que constituyó para el liberalismo político ilustrado el poder fundamental; los otros poderes: ejecutivo, federativo o judicial debían estar en función de aquél, para hacer cumplir sus disposiciones o leyes en el interior del propio país o en relación con otros y para reprimir las inobservancias de las mismas. Se preveía que el legislativo sería el instrumento de recambio del "poder" que reposaba en las manos absolutas de la monarquía y sus acólitos. El traspaso del poder de un grupo restringido de "chapetones" a los "criollos" está subyacente en la idea de 'representatividad', como se desprende de múltiples discursos del tribuno Mejía, particularmente del desarrollado el 29 de diciembre de 1812 en defensa de los acontecimientos, planteamientos y personas que se vieron involucrados en la

43 Se calcula que 32 de los detenidos que se encontraban en las dependencias altas y bajas del edificio fueron asesinados, entre ellos los principales jefes de la Revolución de Quito, Salinas, Quiroga, Larrea, Ascázubi, Morales, Riofrío, Villalobos, entre otros. (En el Centro Cultural se exhibe una escena, tomada de una representación del pintor César Villacrés, en la que se desarrolla el instante en que los próceres son asesinados. Las esculturas fueron hechas por Alexander Barbieri, en cera, en 1970.) Ver, http://kwovadis.com/cliente/centrometro/esp/masacre. $\mathrm{htm}$ organización de la Primera Junta Soberana de Gobierno, que constituyó el primer gobierno criollo en América, como también en similares discursos como los del 13 de octubre de 1813, primero de noviembre, 9 de diciembre, 2 y 3 de enero de 1812 y 28 de abril del mismo año. ${ }^{44}$

Pero el derecho a gobernarse o a ser elegido y elegir, en cuya base hay que situar los principios de la soberanía popular que tanto supo esgrimir la élite ilustrada, por supuesto con las consabidas restricciones que terminaron por depositar tan sólo en manos de los propietarios la representatividad, no juzgó Mejía suficiente sin el ejercicio o apoyo de otros derechos fundamentales, sin los cuales el anterior corría el riesgo de quedar en letra muerta: libertad de imprenta, libertad o tolerancia religiosa, libertad de comercio, libertad para el ejercicio político, etc., como ya se ha señalado, banderas estas y otras más necesarias para el desarrollo también de las Colonias.

Importantes también son sus referencias a la constitución del Consejo del Estado, la integración del Consejo Privado de Ministros y las reglamentaciones concernientes al Consejo de Regencia, etc., con todo lo cual se pensaba apuntalar al Estado de derecho, mediación indispensable para salvaguardar los derechos e intereses de los individuos, especialmente aquellos bienes materiales que por su trabajo se habían apropiado.

En este amplio abanico de derechos, reclamos y propuestas de especial trascendencia fue la lucha por la abolición de la Inquisición y la correspondiente aceptación de la tolerancia religiosa. El

${ }^{44}$ Carlos Paladines, Pensamiento Ilustrado... ob. cit. pp. 53-ss. 
aporte de Mejía en este ámbito también lo realizó en la Corte de Cádiz a partir de un tema que en la actualidad no tiene vigencia, pero que en aquellos tiempos fue emblemático para la caída de la monarquía. Los debates sobre la inquisición, realizados a puerta cerrada, no solo disminuían el poder del clero y de la iglesia en general sino que propiciaban la caída o desplome de la monarquía misma, que afectada en uno de sus principales aliados vio en ello el presagio de su posterior desplome. Además, la caída de la autoridad religiosa abría las puertas a la concepción moderna de la autoridad: más secular que religiosa, más institucional que personalizada, más inclinada al peso de la 'razón' que al "argumento de autoridad", al saber que a la opinión o a la fe. ${ }^{45}$

\section{Décima pauta: la fuerza militar}

Fue preocupación de la Carta Magna establecer una fuerza militar. El Estado en general y Estado moderno en particular para subsistir necesita que sus miembros acaten las decisiones que las autoridades a cargo del gobierno del Estado adopten. Además de la legitimidad de tales decisiones se requiere del apoyo del poder de control y represión que descansa en la fuerza pública. Es bajo esta condición que la fuerza de la autoridad e incluso la 'violencia' que ella puede ejercer, logran legitimidad y respaldo ciudadano.

\footnotetext{
45 En el presente el reto es mayor, a los 'derechos individuales': inviolabilidad de la vida, integridad personal, libre pensamiento, respeto a la honra,... toca sumar los 'derechos sociales': a la educación, al trabajo, a la salud, a la propiedad,... y a todo ello aún hay que sumar los 'derechos colectivos': a vivir en un medio ambiente sano, en un medio intercultural y multiétnico, etc. Si a todo esto se suman las 'garantías constitucionales': jurisdiccionales, de acción de protesta, hábeas corpus, acceso a la información pública, hábeas data, acción por incumplimiento y acción extraordinaria de protección, el desfase entre lo formal y la material puede agrandarse. Ver, Constitución de Montecristi, 2008, Título II: Derechos, Arts. $10-83$ y Título III: Garantías Constitucionales, Arts. 84-94.
}

También estaba de por medio la necesidad de aprovisionamiento de armas y todo tipo de pertrechos, y de endeudamiento externo e interno para su consecución. "La deuda inglesa" contraída para sufragar los ingentes gastos de los ejércitos independentistas, los exorbitantes intereses, las negociaciones con los tenedores y financistas de tales bonos y más jugosos negocios pesaron en el presupuesto del naciente Estado y agravaron su desarrollo por siglos.

La claridad del texto constitucional releva de todo comentario. ${ }^{46}$

\begin{abstract}
Al efecto y siendo absolutamente necesaria una fuerza militar competente para mantener el Reino en respeto, se levantará prontamente una Falanje compuesta de tres batallones de infantería sobre el pie de ordenanza, y montada la primera compañía de Granaderos quedando por consiguiente reforzadas las dos de infantería y el piquete de Dragones actuales. El jefe de la Falanje será Coronel, y nombramos tal a don Juan Salinas, a quien la Junta hará reconocer inmediatamente. Nombramos de Auditor de Guerra con honores de Teniente Coronel, tratamiento de señoría y mil quinientos pesos de sueldo anual, a don Juan Pablo de Arena, y la Junta lo hará reconocer.
\end{abstract}

Undécima pauta: gestión y administración centralizada de las instituciones del

\section{Estado}

El Estado moderno ha estado vinculado al desarrollo de una gestión y administración cada vez más especializada y centralizada de sus servicios y del personal de servidores públicos, burocracia en el buen y mal sentido de la palabra, que requiere para sus acti-

\footnotetext{
${ }^{46}$ Max Weber, El político y el científico, Madrid, Alianza Editorial, 2000, pp. 84-85.
} 
vidades. La creación de una infraestructura administrativa, económica, financiera, militar y diplomática unificada; el establecimiento de un poder central suficientemente fuerte como para poder someter a las antiguas estructuras o poderes feudales, particularmente al poder de la iglesia y la oligarquía y los grupos regionales y locales.

La Carta Magna señala y se podría decir con lujo de detalles el personal que se haría cargo del nuevo Estado: remuneraciones, títulos y prerrogativas. "El Presidente tendrá por ahora y mientras se organizan las rentas del Estado seis mil pesos de sueldo anual, dos mil cada Vocal, y mil el Secretario particular". Los Ministros-Secretarios de Estado fueron tres. El proyecto de Miranda deja a determinación de la Junta lo relativo a sueldos. La Constitución quiteña bajó la remuneración del Presidente de seis mil a cuatro mil pesos y la de 1830 no se pronunció al respecto. No existe aún investigación empírica que detalle número de funcionarios, sueldos, crecimiento y lo haya contrastado con el de finales del período colonial.

\section{Las condiciones materiales}

No ha sido casual dejar para el último el análisis del sistema productivo, de las fuerzas productivas y las relaciones sociales de producción que suplantaron al sistema económico colonial y abrieron las puertas para los primeros pasos de introducción del sistema capitalista en la Audiencia de Quito República del Ecuador, a finales del siglo XVIII e inicios del XIX.

Aunque los textos constitucionales son por demás parcos en lo relativo a la economía y finanzas del nuevo Estado; los informes, cartas y memorias de aquella época e inves- tigaciones relativamente últimas, ${ }^{47}$ coinciden en alto grado, salvo excepciones que confirman la regla, en la descripción del sistema productivo de aquella época por las siguientes notas:

En la Sierra centro norte, marcada a lo largo del S. XVIII por los efectos de la crisis minera de Potosí en un primer momento y posteriormente por la crisis que trajo aparejada la decadencia definitiva de los obrajes quiteños, se habría suscitado como reacción la orientación de la producción hacia el agro, que se convertiría en el soporte estructurador de la economía toda, a finales de la época colonial y en las primeras décadas del XIX. ${ }^{48}$ La reorientación hacia el agro habría desencadenado una serie de efectos: dio pie al interés y valoración de la tierra y a los inicios de consolidación del latifundio; al despegue y estabilización de la facción civil terrateniente como clase dominante; a la disponibilidad de mano de obra indígena ante el cierre de las minas y los obrajes; a la ampliación del mercado interno; a la supervivencia en las haciendas de relaciones de producción de carácter feudal como el "concertaje" que favoreció el control de la fuerza de trabajo indígena,...factores estos y otros más que si no condujeron a una rápida recuperación del circulante y a la superación inmediata de la crisis por la que atravesaba la Audiencia, al menos sirvieron de paliativo e inicios de una formación econó-

\footnotetext{
${ }^{47}$ Para este acápite nos ha sido de especial utilidad los trabajos de Carlos Marchán, Estudio intoductorio, La Economía política del Ecuador durante la Colonia, Quito, Biblioteca Básica de Pensamiento Ecuatoriano, Vol. 15, s.f. p. 13-27. Manuel Miño, La economía colonial, relaciones socio económicas de la Real Audiencia de Quito, Quito, Corporación Editorial Nacional, 1984.Michael Hamerly, Historia social y económica de la antigua provincia de Guayaquil: 1763-1842. Publicación del Archivo Histórico del Guayas, 1973

${ }^{48}$ Carlos Marchán, Estudio introductorio, Ob. Cit. pp. $27-53$.
} 
mica que más tarde que temprano terminó por imponerse.

También en esta área el discurso ilustrado puede ser iluminador. Los análisis de Velasco, Espejo, Carondelet, Selva Alegre, por citar nombres, coinciden con textos y metáforas muy similares en señalar la aguda contracción del circulante que vivía la Audiencia, la carencia de dinero efectivo que hacía retrotraer la economía a los tiempos del trueque y la debilitaba al grado de que "faltándole el oro y faltándole el dinero efectivo, sangre que circulando por las venas mantiene el vigor del mutuo comercio de unos miembros con otros, quede sin vitalidad y sin acción todo el cuerpo". ${ }^{49}$

Ya sea a consecuencia de la crisis de los centros mineros de Potosí y Popayán; ya sea por la caída de la industria textil y el consiguiente cierre de los obrajes; ya sea por la inmisericorde succión de recursos vía impuestos y tributos que supieron realizar los Presientes de la Audiencia; ya sea por la competencia textil europea, la penetración de las manufacturas inglesas, el hecho es que en las últimas décadas del S. XVIII no sólo las condiciones sociales, económicas 0 políticas destruían todo género de esperanza, sino que hasta los elementos físicos: terremotos, incendios y epidemias hicieron su agosto sobre la sierra centro y norte.

La región litoral vivió otra dinámica. "Sobre todo a partir de la década de 1770 en que se decreta la libertad de comercio con el resto de las colonias y especialmente con la Nueva España, será el resurgir y auge de la producción y exportación cacaotera". ${ }^{50} \mathrm{El}$ primer boom cacaotero: $1760-1830$, trajo

49 Citado por Manuel Miño, ob. cit. p. 73. Cfr. Carlos Paladines, Espejo conciencia crítica de su época, ob. cit. pp. 171-ss.

${ }^{50}$ Ibíd., p. 77. aparejado el desarrollo de la construcción naviera; el crecimiento del puerto de Guayaquil; la expansión del latifundio que se convirtió en la forma dominante de posesión de tierras en las planicies del Guayas y el litoral sur; ${ }^{51}$ la multiplicación de propietarios y ganaderos con terrenos medianos y pequeños, la dinamización de otros varios sectores económicos y sociales hasta entonces a ritmo por demás lento de crecimiento y, lo más importante, el cacao fue el motor a través del cual se movilizaría la fuerza de trabajo de la Sierra, cuya economía pasaba por agudo estancamiento. El sostenido crecimiento de las exportaciones que algunos años llegó a representar las dos terceras y hasta las tres cuartas partes de las exportaciones también repercutió en el crecimiento demográfico. "Entre 1765 y 1839/40 la población de la costa casi de cuadruplicó, aumentado de por lo menos 22.445 a 86.206 habitantes". En definitiva, se abrieron las puertas a una "revolución agrícola cuya importancia en la historia del Ecuador ha sido desde hace mucho tiempo vislumbrada pero nunca estudiada como se merece". ${ }^{52}$

El Austro: Cuenca y Loja también disfrutaron de años de bonanza. Loja se repuso de la caída de sus minas gracias a la cascarilla, producto sobre el cual giró su economía, aunque esa primavera le duró muy poco. Además se distinguió por ser la proveedora más importante de mulas, el principal medio de transporte, y algo también gracias al tabaco. Para el caso de Cuenca, la intermediación en el comercio de la cascarilla, el aguardiente, el ganado vacuno, los tejidos, el remate de tributos y el intercambio de artículos manufacturados, objeto del comercio exterior, permitieron

\footnotetext{
${ }^{51}$ Michael Hamerly, ob. cit. pp. 105-108.

${ }^{52}$ Ibíd., pp. 67 - 112 y 79.
} 
establecer más estrechas relaciones con Guayaquil, Lima y el norte del Perú, lo que a su vez permitió un repunte económico vía intercambio comercial.

Esta descripción, un tanto general, sería incompleta de no tomarse en cuenta una serie de tendencias que acompañaron al nacimiento de la nueva matriz productiva. Por una parte, la migración hacia el litoral de población indígena que en pocos años hizo triplicar la población de la Costa y disponga ella de mano de obra para sus plantaciones; por otra, el auge de las exportaciones de la "pepa de oro" vino a paliar las pérdidas ocasionadas por la crisis minera y de las manufacturas, ampliando así las posibilidades de acumulación de capital comercial en el Puerto. En tercer lugar, la consolidación de un circuito comercial en torno al puerto de Guayaquil, que a su vez conectaba a Quito con el comercio del Pacífico, terminó por arrastrar tras de sí a la economía de toda la Sierra en calidad de complementaria. En cuarto lugar, la nueva matriz no logró alterar en forma inmediata la sobrevivencia de relaciones semi-feudales en las haciendas, sobre todo serranas. Además se continuó con la dependencia comercial de Lima que monopolizaba gran parte de los beneficios generados y de la construcción naval porteña.

El lento articularse de todas las nuevas fuerzas productivas y regionales en una nueva matriz no alteró de inmediato la vía de acumulación de los recursos fiscales. Los aparatos del Estado siguieron alimentándose de los impuestos, vía remate del aguardiente, las alcabalas, las aduanas, el papel sellado y en cerca del $50 \%$ del presupuesto por el tributo de indios, práctica poco moderna y claramente discriminatoria y medieval. De todos los ramos de imposición el referente al "Real Tributo de Indios" parece que fue el fundamental, "no solo necesario sino verdaderamente indispensable" en palabras de González Suárez. Recién el Congreso de 1857, según Pío Jaramillo Alvarado, y en 1895 según Oscar Efrén Reyes se lo suprimió. ${ }^{53}$

En este escenario de cambio de la matriz productiva, pero cuyos beneficios o bondades tardaban en llegar, el nuevo Estado de Quito se vio presionado desde sus primeros días a ordenar sus escasos ingresos y a buscar nuevos recursos para sobrevivir. La tabla de salvación en tan dramática descomposición se juzgó que provendría de la "libertad de comercio" reclamada fervorosamente por "sirios y troyanos". Tampoco que yo conozca existe investigación empírica sobre las finanzas del naciente cuerpo político y el resultado de sus líneas de acción o si continuó el sistema tradicional actuando con lo que se habría generado una "modernización-tradicional" o "progresismoconservador" o "modernidad retrógrada", entendiendo por tal aquella en la que se alteran las formas mas no el fondo, se conservaba el poder y se cedía en aspectos menores. ${ }^{54}$

En todo caso, las constituciones de 1809 y 1812 e incluso la de 1830 no prestaron mayor atención a las condiciones materiales que estaban Ilamadas a apuntalar lo conquistado de modo tan costoso en el orden

\footnotetext{
53 Carlos Paladines, Espejo conciencia crítica de su época, ob. cit. p. 196.

54 En los últimos tiempos diversos autores han recurrido a este tipo de explicación. Ver, Álvaro Campuzano Arteta, "Sociología y misión pública de la universidad en el Ecuador". en Espacio público y privatización del conocimiento, Buenos aires, CLACSO libros, 2005, p. 406. Fernando Trazegnies ha examinado este carácter contradictorio de los procesos de modernización -"tradicionalista". Cfr. "Las tribulaciones de las Ideas, preocupaciones en torno a la idea de Derecho en el Perú Republicano del S. XIX, en: Rev. De Historia de las Ideas, No. 7. Edit. CCE y Centro de Estudios Latinoamericanos de la PUCE, 1986.
} 
jurídico y político. Mérito de la Constitución quiteña de 1812 es haber dedicado al menos tres artículos: 23-25: "Al Poder Ejecutivo corresponde velar sobre la recaudación de los caudales públicos, custodia y adelantamiento del Tesoro Nacional y su inversión” y con visión de futuro añadió: “ de todo lo que presentará al público todos los años una razón impresa que circulará por todas las Provincias, comprensiva del ingreso, existencia, motivos de su inversión y gastos, y en cada bienio el cotejo del estado antecedente de las rentas públicas con el que tuvieren en aquella fecha". ${ }^{55}$ En el caso de México, Hidalgo y sus compañeros, en su trágico y breve itinerario, lograron dictar una serie de medidas de alta trascendencia económica y social como la abolición de la esclavitud, el goce exclusivo de las tierras de comunidad por los indios, la extinción del tributo, del estanco de pólvora y papel sellado,... ${ }^{56}$

\section{La superación de las adversidades}

No se han valorado las dificultades $y$ limitaciones que hubo que vencer en este proceso de gestación. La historiografía se ha detenido en los méritos políticos que sin lugar a dudas son dignos de encomio y constituye uno de los más excelsos procesos de liberación de nuestra historia; ha sabido resaltar la faceta política de las constituciones que acompañaron a las gestas de agosto, pero ha sido más cauta en el análisis de las limitaciones, adversidades y dispersión que se requirió superar. Construir el nuevo Estado no fue tarea ni fácil ni sencilla. Valga señalar algunas limitaciones sin pretensiones ni de

\footnotetext{
${ }^{55}$ Constitución quiteña de 1812, ob. cit. p. 17.

${ }^{56}$ Ernesto de la Torre Villar, "El origen del Estado mexicano", en Problemas de la formación del Estado $y$ de la Nación en Hispanoamérica, ob. cit. p. 136.
}

agotar la crítica ni de ordenarla jerárquicamente:

En primer lugar, "La estructura económica y las relaciones sociales cambiaron poco en el tránsito de la Colonia a la República". Resultó contradictorio proclamar a través de los textos constitucionales la independencia, la libertad y la igualdad de las personas y en la práctica no alterar las estructuras y relaciones inequitativas de producción. ${ }^{57} \mathrm{El}$ desfase entre las nuevas fuerzas productivas y las relaciones sociales de producción con las centenarias estructuras coloniales opuestas al cambio continuó en vigencia y el paso a sociedades organizadas estatalmente chocó con la dinámica de los intereses individuales y locales. Para la gran mayoría de la población continuaron con vigencia las relaciones feudales y la explotación de la fuerza de trabajo, sobre todo indígena.

Cabe resaltar que un Estado naciente, en serias dificultades económicas si bien aniquiló viejos moldes monárquicos o coloniales no tuvo igual brillantez para desencadenar su desarrollo económico. Esta fue una de sus debilidades. El nacimiento del Estado moderno no estuvo unido al de una economía destinada a sustentarlo financieramente, es decir, a hacer frente a los gastos necesarios para mantener funcionarios a sueldo, sostener un ejército mercenario, desplegar una política interior y exterior mucho más activa y costosa que la de los tiempos precedentes y dinamizar las nuevas fuerzas económicas emergentes. El Estado no fue capaz de consolidar una matriz productiva, reglar y dirigir la economía en su propio seno, en medio de tres regiones en diferente grado, modelo y rela-

\footnotetext{
${ }^{57}$ Enrique Ayala, Manual de Historia del Ecuador, Época Republicana, II, Quito, Corporación Editora Nacional, 2008, p. 10.
} 
ciones de producción; tampoco pudo establecer vías de comunicación que permitiesen romper el aislamiento que en determinadas épocas del año interrumpía las comunicaciones de una región con otra, por semanas y meses. Tampoco se logró implantar un sistema aduanero y normas precisas que controlen la entrada y salida de los productos. En forma inmediata fue presa de la inestabilidad, las pugnas internas y el enfrentamiento fratricida que caracterizó a las primeras décadas de vida republicana.

En segundo lugar, otra posible limitación fue que no se dispuso de la claridad operativa requerida a fin de que al "¿qué hacer"? expuesto con claridad en los textos constitucionales estuviese vinculada la previsión del "¿cómo hacer"? La claridad programática no tuvo su debido correlato o plan operativo como ha sido costumbre de muchas Constituciones: brillantes en su parte dogmática o doctrinal, mientras lo correspondiente a la organización o estructura ha representado su permanente debilidad. Lo certifican más de veinte constituciones, ricas en la parte doctrinal y pobres en su capacidad de concreción de los "sueños".

En tercer lugar, el reducido desarrollo de la ciudadanía y del número de ciudadanos. Los ejes de articulación y cohesión del nuevo Estado se orientaron más al cultivo de los valores de vecindad: los tesoros de nuestra geografía, las glorias del pasado que a los requisitos mínimos de ciudadanía: instrucción, bienes, trabajo, propiedad, participación y deliberación,... ¿Qué futuro podía tener una sociedad moderna sin ciudadanos, con población rural más que urbana e incluso en las urbes con una composición poco favorable a la gestión y participación ciudadana? Más aún, la Constitución de 1830 expresamente cerró las puertas a la mayoría de la población: al sirviente doméstico, al jornalero, al analfabeto, a todos quienes no tenían una propiedad de más de trescientos pesos e incluso a quienes debían a los fondos públicos o habían sido declarados vagos, ebrios de costumbre o enajenados mentales. ${ }^{58}$ Fue contradictoria: por un lado reclamaba ciudadanía y por otro cerraba las puertas a la misma. Además permitió la continuidad de leyes, fueros como el eclesiástico y el militar y hasta servicios personales que si bien en el texto constitucional fueron rechazados, en la práctica continuaron hasta muy avanzado el siglo XX. La Ley de Indias también en la práctica continuó vigente, pues el nuevo Código Republicano - Napoleónico se expidió varias décadas después. ${ }^{59}$

En definitiva, el proyecto ilustrado fue excluyente y llevado adelante por un grupo restringido de ciudadanos. No fue capaz de garantizar las condiciones para el pleno ejercicio de los derechos civiles de la mayoría de la población. Amplios sectores no se involucraron y permanecieron al margen. Se excluyó a indios, negros, mestizos y mujeres y se mantuvo la sociedad fuertemente jerarquizada.

En cuarto lugar, el modelo de Estado y Nación que se trató de llevar adelante fue dirigido "desde arriba" (vía junker) y los permanente levantamientos y asonadas militares deslizó los planteamientos paulatinamente a postular medidas drásticas; sin las cuales se creía que no era factible implementar los proyectos y así “cerrar el cráter de la revolución y fijar la paz bajo los auspicios de la libertad; se necesita aquí mucha fuerza y un rigor que

\footnotetext{
${ }^{58}$ Federico Trabucco, Constituciones de la República del Ecuador, Quito, Edit. Universitaria, 1975, Constitución de 1830, arts. 12 y 13.

${ }^{59}$ Véase, Constitución de 1830 , arts. 58 y 62 .
} 
toque en crueldad para sofocar el espíritu anárquico que atormenta esta sociedad. A desesperados males, desesperados remedios". El despotismo ilustrado y la minusvaloración de la plebe tomó así carta de ciudadanía. ${ }^{60}$

En quinto lugar, la ética del "trabajo disciplinado", "la planificación", "el cálculo", la "racionalidad sistemática", la "razón instrumental", el "respeto a ley" y al "Estado de Derecho", el "proceso de secularización",... no coparon el espacio nacional. Se dieron muestras reiterativas de ser un pueblo refractario por "naturaleza" a tal tipo de comportamiento, y a cada proyecto o intento de modernización se levantó una sorda resistencia de parte de una sociedad predominantemente agraria, mezcla sui generis del pasado con el presente, de la tradición con la modernidad, de los valores de uso con los de cambio, "modernización tradicionalista o retrógrada" en que predominaba el maquillaje sobre los cambios de fondo; el disfrute referido al valor de uso o valor "natural" de los bienes más que al valor de cambio y acumulación de capital. ${ }^{61}$

El ingenuo "optimismo ilustrado", que juzgó que la claridad de la teoría arrastraría fácilmente a la práctica y que a los principios morales se plegarían fácilmente las nuevas autoridades, dio claras muestras de limitación. La élite post independentista como el dios Jano tuvo doble cara: una de ellas miraba al oprobioso, obsoleto e ineficiente pasado colonial a sepultar; la otra se fijó en el futuro, en la tierra prometida: un nuevo Estado que reemplazaría las estructuras del pasado, pero de lo que

\footnotetext{
${ }^{60}$ Carlos Paladines, El movimiento ilustrado y la independencia de Quito, Quito, Editor FONSAL, 2009, p. 146.

61 Ver, Álvaro Campuzano Arteta, "Sociología y misión pública de la universidad en el Ecuador", art, cit. p. 406.
}

disfrutaría solo un reducido número de ciudadanos.

En cualquier caso, en medio de las más graves adversidades, tanto en el frente interno como externo e incluso en medio de las barreras que las cadenas montañosas imponían a la comunicación y a la constitución de una red vial nacional, y un lento crecimiento demográfico $y$ productivo, el país no dejó de hacerse y construirse. Pese a todo y otras adversidades más, el Ecuador logró superar esta aciaga fase de génesis o constitución de la República del Ecuador. Esta capacidad para superar todo tipo de aflicciones la ha descrito en fórmula ya clásica el historiador Salvador Lara. Nos permitimos reproducirla a pesar de su extensión:

El avance ha sido lento pero no desalentador; pese a errores, retroceso, fracasos y aún quiebras el hombre ecuatoriano ha sabido ampliar su dominio sobre el suelo, integrando poco a poco su espacio territorial $y$ aproximándose efectivamente a la línea que nos queda de jurisdicción territorial. No han sido óbice para ese sostenido esfuerzo ni las catástrofes de la naturaleza (terremotos, maremotos, aluviones, períodos de sequía, pestes, invasiones piráticas, agresiones armadas desde el exterior, guerras civiles, etc.); ni las frustraciones colectivas originadas por la brusca cesación del proceso unificador Cara, el asesinato de Atahualpa -reivindicador de Quito frente al Cuzco-, las ambiciones sucesivas y manejos contrarios a la Real audiencia de Quito, por parte de los Virreyes del Perú y Nueva Granada; ni la expulsión de los jesuitas,(...); ni el desangre durante la independencia -masacre del 2 de agosto, fusilamientos y persecuciones por Montes, Ramírez y Aymerich, aportes económicos y en hombres a la libertad del Perú-, campañas de Tarqui y Buijo, ni el asesinato de Sucre; ni la ley de división territorial con que Santander cercenó a la antigua Presidencia de Quito en 1824, en beneficio de Cundinamarca, 
los territorios de Cali, Popayán y Pasto; ni la agresión peruana del Mariscal Castilla que empezó a esgrimir con falsa interpretación la cédula de $1802 .{ }^{62}$

\section{Las Constituciones de febrero (Quito) y de marzo (Cádiz) de 1812}

Una vez examinados algunos aportes de la Constitución Quiteña paso a contrastarla con la Constitución Política de la Monarquía Española, Constitución de Cádiz.

Aclaración previa. Por regla general se suele presentar a dicha Constitución como la base o punto de partida del Estado moderno español al haber establecido la soberanía popular, la división de poderes, la libertad de expresión, de imprenta,... y haber abolido la Inquisición. "La Constitución de 1812 proclamó que los españoles ya no eran súbditos, sino ciudadanos, ciudadanos libres e iguales en derechos y deberes. Dejaba atrás así la filosofía del Antiguo Régimen y ponía la libertad y la soberanía popular en el vértice de todo el edifico constitucional". ${ }^{63}$ También se asigna a esta constitución el haber ejercido un benéfico influjo o huella en América. Más de un autor ha juzgado que la Constitución de Cádiz, 'La Pepa' se convirtió “en un símbolo de la libertad, no solo en nuestro continente sino hacia el exterior por su repercusión en los países Iberoamericanos". 64

${ }^{62}$ Véase, J. P. Deler, N. Gómez y M. Portais, El manejo del espacio en el Ecuador-etapas claves. Ecuador, Edit. Instituto Panamericano de Geografía e Historia, 1983, Prefacio.

${ }^{63}$ Comisión Nacional para la Conmemoración del II Centenario de la Constitución de 1812, La Pepa 2012. El Espiritu de Cádiz. p.5.

${ }^{64}$ Es posible que la Constitución de Cádiz haya ejercido un benéfico influjo o huella en América como se sostiene en la obra: La constitución de 1812 y su huella en América. El libro recoge distintos estudios que avalan el impacto y la
Para el caso ecuatoriano esto no corre, por la sencilla razón de que la primera Constitución de Quito fue promulgada años antes, en 1810, y la Constitución quiteña meses antes de la promulgación de la de Cádiz. Esto no significa desconocer el posible influjo de Cádiz a través de los "diputados ultramarinos" quienes al regreso a sus países debieron haber utilizado su experiencia en España para el desarrollo de los diferentes procesos constituyentes hispanoamericanos; tampoco significa desconocer la inferioridad numérica y muy bajo número de representantes de las colonias, lo cual dificultó su actividad parlamentaria y reivindicativa que se puso de manifiesto en múltiples debates.

Pero no se trata sólo de diferencias de tiempos, de años, meses o días; también las diferencias vienen marcadas por la ruptura mayor o menor con la monarquía y con la iglesia. La Constitución de Cádiz inicia con el recurso a Fernando VII, quien la decreta y sanciona: "Don Fernando VII, por la gracia de Dios y la Constitución de la Monarquía española". Además, la Constitución de Cádiz dedica un título exhaustivo al Rey, Título IV, Arts: 168-221. y los siguientes capítulos a la monarquía: Cap. I: De la inviolabilidad del Rey y de su autoridad; Cap. II: De la sucesión a la Corona; Cap. III: De la menor edad del Rey, y de la Regencia; Cap. IV: De la familia real y del reconocimiento del Príncipe de Asturias; y Cap. V: De la

trascendencia de la dicha Constitución en todo el continente americano. En la presentación, en Cádiz, Diego Sales, Rector de la Universidad de Cádiz declaró que "la ciudad portuaria de Cádiz desplegó las velas de la libertad y exportó democracia por todo el continente americano. Nunca una ciudad sitiada llegó tan lejos en sus proclamas y en sus ambiciones". 
dotación de la familia real. Además otorga al Rey la prerrogativa de sancionar y permitir que entren en vigencia las leyes, Art. 142. En cuanto a las facultades del Rey, la Constitución de Cádiz es más que generosa: dieciséis. Por motivos de espacio y tiempo se citan solo algunas: "Nombrar los magistrados de todos los tribunales civiles y criminales, a propuesta del Consejo de Estado; Proveer todos los empleos civiles y militares; Presentar para todos los obispados, y para todas las dignidades y beneficios eclesiásticos de real patronato, a propuesta del Consejo de Estado; Decretar la inversión de los fondos destinada a cada uno de los ramos de la Administración pública". No faltaron las restricciones a la autoridad del Rey y ellas fueron doce, Art. 171.

Por otra parte, La Constitución de Cádiz, en materia religiosa fue una constitución confesional e intolerante; prohibía el ejercicio de otras religiones que no sea la católica. Art. 12: «La religión de la Nación española es y será perpetuamente la católica, apostólica, romana, única verdadera. La Nación la protege por leyes sabias y justas y prohíbe el ejercicio de cualquier otra». Un constitutivo tan claro del Estado moderno como es la separación de la Iglesia del Estado, del trono del altar, no logró imponerse, a pesar del carácter liberal, en otros ámbitos de la misma, debido a la composición de las Cortes y los débiles equilibrios entre los sectores reaccionarios y otros más liberales. Para algunos autores, con este artículo se plasmó una de las fórmulas más intransigentes de toda la historia constitucional española.

\section{Lecciones para el presente}

A la fecha han transcurrido alrededor de dos siglos desde el primer grito de independencia de América -Bicentenario- , y se han formulado y aprobado más de veinte constituciones; se ha interrumpido o quebrado el orden constitucional en forma reiterada y no faltan opiniones sobre la escasa penetración en nuestra vida diaria o cotidiana del respeto a la ley y al Estado de derecho y más bien, al menos en los últimos años ha crecido la opinión de que el sistema constitucional a pesar de que su última Carta data del 2008 y de los logros ya alcanzados, requiere de urgentes reformas.

También en los últimos tiempos gana adeptos la tesis de que asistimos al final del modelo o matriz productiva de carácter agroexportador y extractivista de materias primas que dio en "aquellos tiempos" sus primeros pasos y ha caracterizado al país a lo largo de estos dos últimos siglos. En las sociedades actuales, con ultra ciencia y meta tecnología, cobertura mundial de información y comunicación, economía y finanzas globales,... el Estado moderno se habría vuelto obsoleto, parecido a lo que aconteció con el Estado colonial. Hoy, inicios del S. XXI, se haría cada vez más necesaria una nueva matriz productiva, aquella que es propia de las "sociedades del conocimiento" según los términos últimos de moda.

En esta perspectiva o escenario puede ser iluminador examinar e investigar los primeros pasos de nuestra rica vida constitucional, en la cual pueden esconderse tanto las raíces de algunas de nuestras desventuras como de ciertas posibles soluciones. En pocas palabras, a la riqueza del Primer Grito de Independencia que hizo de Quito 'Luz de América', hay que sumar y asumir para su mejor comprensión y valoración el legado histórico correspondiente a las primeras constituciones quiteñas, tanto la de 1809 como la de 1812, ámbito jurídico éste que 
fue necesario aunque no suficiente para la construcción del Estado moderno en el Ecuador.

\begin{tabular}{|c|c|c|c|c|}
\hline \multicolumn{5}{|c|}{ Anexo No. 1: POBLACIÒN DEL ECUADOR 1779/1780- 1857/1858 } \\
\hline DIVISIONES ADMINISTRA & $1779 / 1780$ & 1825 & $1838 / 1840$ & $1857 / 1858$ \\
\hline ESMERALDAS & $2.497^{\mathrm{a}}$ & $2.352^{i}$ & $5.229^{p}$ & $6.429^{x}$ \\
\hline MANABì & $(7.699)^{b}$ & {$[17.444]^{j}$} & $23.641^{q}$ & $30.208^{y}$ \\
\hline GUAYAQUIL & $(22.644)^{b}$ & {$[55.048]^{k}$} & {$[62.565]^{r}$} & $91.620^{2}$ \\
\hline IBARRA & $16.585^{\mathrm{c}}$ & 25.492 & $39.007^{p}$ & $75.285^{x}$ \\
\hline OTAVALO & $32.060^{c}$ & $(33.233)^{1}$ & $45.734^{p}$ & {$[82.915]^{x}$} \\
\hline QUITO & $59.391^{c}$ & {$[65.605]^{\|}$} & {$[72.712]^{\mathrm{s}}$} & $77.498^{x}$ \\
\hline LATACUNGA & $49.919^{c}$ & $55.814^{\mathrm{m}}$ & {$[74.505]^{\text {tç }}$} & $69.539^{x}$ \\
\hline AMBATO & $43.372^{c}$ & $37.495^{m}$ & {$[66.155]^{u}$} & \\
\hline RIOBAMBA & $66.776^{c}$ & $51.137^{m}$ & - & $120.314^{x}$ \\
\hline GUARANDA & $14.368^{c}$ & $15.006^{m}$ & {$[83.965]^{v}$} & \\
\hline ALAUSÍ & $11.960^{d}$ & $10.338^{\mathrm{m}}$ & & \\
\hline CUENCA & {$[82.708]^{\mathrm{e}}$} & {$[75.785]^{n}$} & {$[102.689]^{w}$} & $120.407^{x}$ \\
\hline LOJA & $23.810^{c}$ & $34.305^{n}$ & $41.090^{v}$ & $71.082^{x}$ \\
\hline SUBTOTALES & [433.789] & [477.054] & [617.192] & {$[748.297]$} \\
\hline QUIJOS & $3.264^{f}$ & {$[2.976]^{\circ}$} & & \\
\hline MACAS & $643^{g}$ & $443^{m}$ & & \\
\hline MAYNAS & $(9.270)^{h}$ & $8.000^{11}$ & & \\
\hline TOTALES & [446.966] & [488.473] & & \\
\hline
\end{tabular}

Fuente: Michael Hamerly, Ob. Cit. pp. 80- 83 y 121-122.

\begin{tabular}{|c|c|c|c|c|c|c|c|c|c|c|c|}
\hline \multicolumn{12}{|c|}{ DISTRIBUCIÓN DE LA POBLACIÓN POR REGIONES: 1780-1825 } \\
\hline & \multirow[t]{2}{*}{ Costa } & \multirow[t]{2}{*}{ Sierra } & \multirow[t]{2}{*}{ Oriente } & \multirow[t]{2}{*}{ Total } & \multicolumn{4}{|c|}{$\begin{array}{l}\text { Población Futura de la Real Audiencia de Quito } \\
\text { en la Gran Colombia }\end{array}$} & \multicolumn{3}{|c|}{ Crecimiento anual } \\
\hline & & & & & Blancos & Indígenas & $\begin{array}{l}\text { Pardos } \\
\text { libres }\end{array}$ & Esclavos & Costa & Sierra & Oriente \\
\hline 1780 & 31.500 & 405.000 & 13.500 & 450.000 & 157.000 & 393.000 & 42.000 & 8.000 & 7 & 90 & 3 \\
\hline 1810 & 67.500 & 515.100 & 17.400 & 600.000 & & & & & 11.25 & 85.85 & 2.9 \\
\hline 1825 & 74.400 & 391.160 & 13.440 & 480.000 & & & & & 15.5 & 81.7 & 2.8 \\
\hline 1840 & 85.800 & 547.300 & 16.900 & 650.000 & & & & & 13.2 & 84.2 & 2.6 \\
\hline 1860 & 127.500 & 603.750 & 18.750 & 750.000 & & & & & 17 & 80.5 & 2.5 \\
\hline
\end{tabular}

Fuente: Enrique Ayala Mora, Editor, Nueva Historia del Ecuador, Quito, Corporación Editora Nacional, Vol. 6, p. 134.

\begin{tabular}{|c|c|c|c|}
\hline \multicolumn{4}{|c|}{$\begin{array}{l}\text { Anexo No. 2: EXPORTACIONES E IMPORTACIONES POR EL PUERTO DE GUAYAQUIL: } \\
\qquad 1821-1825\end{array}$} \\
\hline \multicolumn{3}{|c|}{ EXPORTACIONES } & TOTAL DE IMPORTACIONES \\
\hline AÑO & CACAO & OTROS & \\
\hline 1821 & 471.788 ps. 7 rs. & 207.969 ps. $1 / 2$ rl. & 346.845 ps. $1 \frac{1}{2} \mathrm{rl}$. \\
\hline 1822 & 616.967 ps. 6 rs & 301.803 ps. $4 \frac{1}{2} r$ & 1.408 .740 ps. $21 / 2 \mathrm{rl}$. \\
\hline 1823 & 591.566 ps. 4 rs & 514.727 ps. 5 rl. & $1.624 .181 \mathrm{ps} .61 / 2 \mathrm{rl}$. \\
\hline 1824 & 441.575 ps. 3 rs & 588.539 ps. $51 / 2 r$ & 1.319 .027 ps. 1 1⁄2 rl. \\
\hline 1825 & $367.208 \mathrm{Ps}$ & 561.927 ps. $1 \mathrm{rl}$. & 1.051 .285 ps. $1 \frac{1}{2} \mathrm{rl}$. \\
\hline
\end{tabular}

Fuente: Michael Hamerly, Historia social y económica de la antigua provincia de Guayaquil: 1763 -1842. Guayaquil, Publicaciones del Archivo Histórico de Guayas, 1973, p. 136 


\begin{tabular}{|c|c|}
\hline \multicolumn{2}{|c|}{ COSECHA ANUAL PROMEDIA DE CACAO: 1700-1825 } \\
\hline AÑO & COSECHA EN CARGAS \\
\hline $1770-1718$ & $34.000^{\mathrm{a}}$ \\
1719 & $18.000^{\mathrm{a}}$ \\
$1729-1736$ & $35.000^{\mathrm{b}}$ \\
$1737-1741$ & $40.000-50.000^{\mathrm{b}}$ \\
1765 & $34.060^{\mathrm{d}}$ \\
$1772-1779$ & $40.000^{\mathrm{a}}$ \\
$1780-1790$ & $56.000^{\mathrm{a}}$ \\
1802 & $100.000^{\mathrm{e}}$ \\
1809 & $150.000^{\mathrm{f}}$ \\
$1821-1825$ & $180.000-190.000^{\mathrm{g}}$ \\
\hline
\end{tabular}

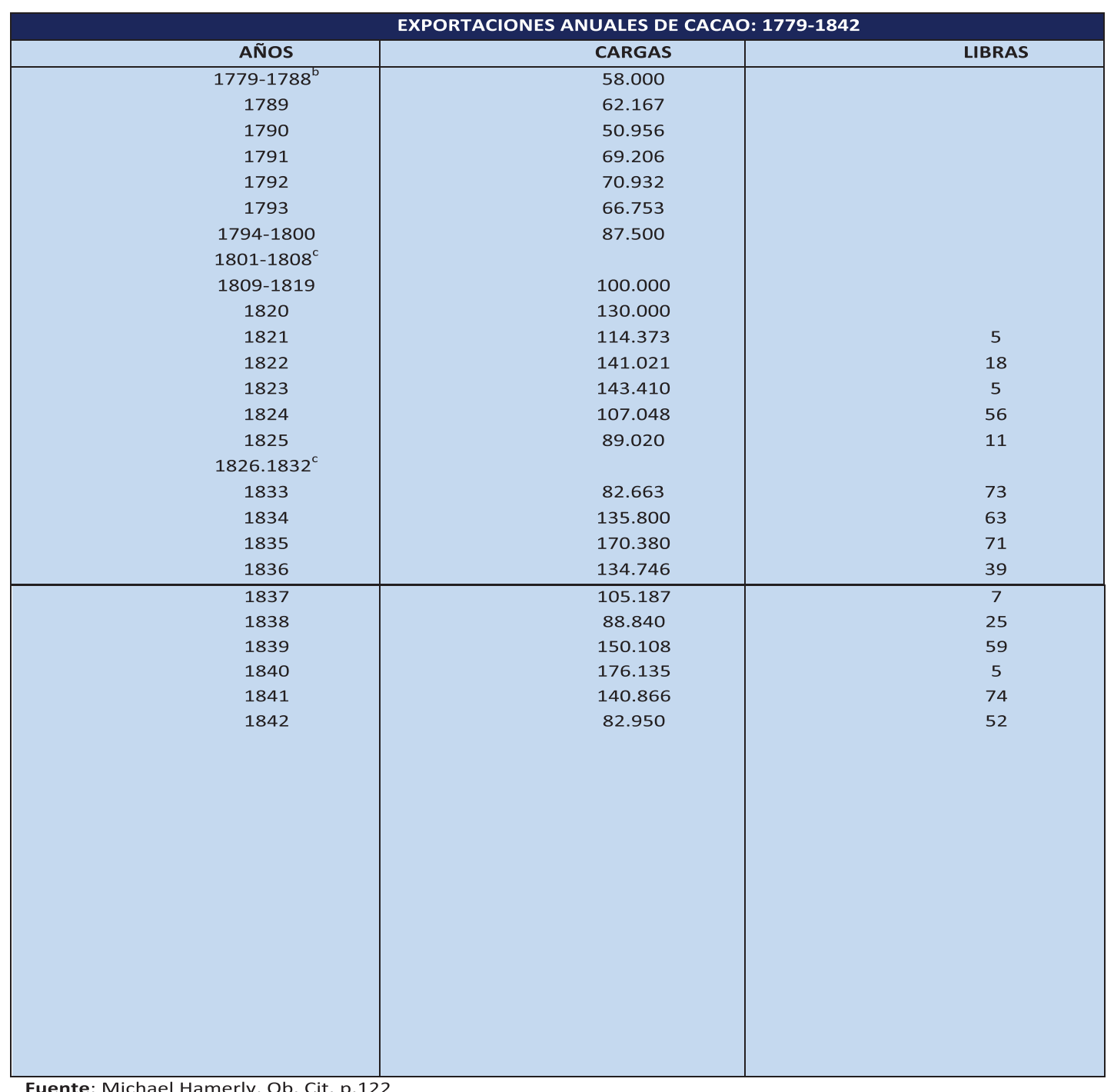




\begin{tabular}{|c|c|c|c|c|}
\hline $\begin{array}{l}\text { CONSTITUCION DE LOS ESTADOS UNI- } \\
\text { DOS DE AMERICA: } 17 \text { de septiembre de } \\
1787\end{array}$ & $\begin{array}{l}\text { CONSTITUCIÓN DE LA JUNTA } \\
\text { SUPREMA GUBERNATIVA DEL } \\
\text { REINO DE QUITO, Acta del } 10 \\
\text { de agosto de } 1809^{65}\end{array}$ & \begin{tabular}{ll} 
& \multicolumn{2}{c}{ Anexo No. 3: Es } \\
CONSTITUCIÓN QUITEÑA: 15 de \\
febrero de 1812
\end{tabular} & $\begin{array}{l}\text { ructura Constituciones } \\
\text { PROYECTO CONSTITUCIÓN: Calixto } \\
\text { Miranda: enero } 1812\end{array}$ & $\begin{array}{l}\text { CONSTITUCIÓN DE CÁDIZ: } 18 \text { de marzo } \\
\text { de } 1812\end{array}$ \\
\hline \multirow[t]{2}{*}{ Declaración o preámbulo. } & & Declaración o preámbulo. & Introducción o preámbulo & Declaración o preámbulo. \\
\hline & $\begin{array}{lcl}\text { DE } & \text { LA } & \text { ASAMBLEA } \\
\text { CONSTITUYENTE. } & \end{array}$ & $\begin{array}{lccc}\text { Sección } & \text { primera: } & \text { DEL ESTADO DE } \\
\text { QUITO Y Y SU } & \text { REPRESENTACIÓN } \\
\text { NACIONAL } & & \\
\end{array}$ & I.- DEL REINO Y SU SOBERANÍA & $\begin{array}{l}\text { Título 1: DE LA NACION ESPAÑOLA Y } \\
\text { DE LOS ESPAÑOLES }\end{array}$ \\
\hline Artículo uno: PODER LEGISLATIVO ${ }^{66}$ & $\begin{array}{llr}\text { SUS } & \text { MINISTROS } & 0 \\
\text { SECRETATIOS } & \text { DE } & \text { ESTADO } \\
\text { (Ejecutivo) } & & \end{array}$ & $\begin{array}{l}\text { Sección Segunda: DEL PODER } \\
\text { EJECUTIVO. }\end{array}$ & $\begin{array}{l}\text { II.-DEL SENADO SUPREMO (Legislativo } \\
\text {-Ejecutivo) }^{67}\end{array}$ & $\begin{array}{l}\text { Título II: DEL TERRITORIO DE LAS } \\
\text { ESPAÑAS, SU RELIGION Y GOBIERNO Y } \\
\text { DE LOS CIUDADANOS ESPAÑOLES }\end{array}$ \\
\hline Artículo dos: PODER EJECUTIVO & $\begin{array}{l}\text { DE SUS REPRESENTANTES } \\
\text { (Legislativo) }\end{array}$ & $\begin{array}{llll}\text { Sección tercera: } & \text { DEL } & \text { PODER } \\
\text { LEGISLATIVo } & & \\
\end{array}$ & III.- DEL TRIBUNAL DE JUSTICIA & Título III: DE LAS CORTES (Legislativo) \\
\hline Artículo tres: PODER JUDICIAL & $\begin{array}{l}\text { DE LA ADMINISTRACION DE LA } \\
\text { JUSTICIA (Judicial) }\end{array}$ & Sección cuarta: DEL PODER JUDICIAL & IV.- DEL PATRONATO ECLESIÁSTICO & Título IV: DEL REY (Ejecutivo) \\
\hline Artículo cuarto: ESTADOS FEDERADOS & $\begin{array}{l}\text { DE LA POBLACIÓN } \\
\text { TERRITORIO }\end{array}$ & & 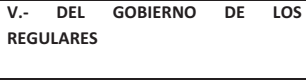 & $\begin{array}{l}\text { Título V: DE LOS TRIBUNALES Y DE LA } \\
\text { ADMINISTRACION DE JUSTICIA EN LO } \\
\text { CIVIL Y CRIMINAL (Judicial) }\end{array}$ \\
\hline $\begin{array}{l}\text { Artículo quinto: } \\
\text { CONSTITUCIONALES }\end{array}$ & DE LA RELIGIÓN & & VI.- DEL CABILDO SECULAR & $\begin{array}{l}\text { Título VI: DEL GOBIERNO INTERIOR DE } \\
\text { LAS PROVINCIAS Y DE LOS PUEBLOS }\end{array}$ \\
\hline $\begin{array}{l}\text { Artículo sexto: SOSTENIMIENTO DE LA } \\
\text { CONSTITUCIÓN SIN } \\
\text { RELIGIOSA }\end{array}$ & DE LA FUERZA MILITAR & & VII.- DE LAS RENTAS DEL REINO & Titulo VII: DE LAS CONTRIBUCIONES \\
\hline $\begin{array}{lllll}\text { Artículo siete: } & \text { VIGENCIA } & \text { DE } & \text { LA } \\
\text { CONSTITUCIÒN } & & & \\
\end{array}$ & $\begin{array}{l}\text { DE LA JUNTA SUPREMA } \\
\text { (De la vigencia). }\end{array}$ & & VIII.- DEL ARMAMENTO DEL REINO & $\begin{array}{l}\text { Título VIII DE LA FUERZA MILITAR } \\
\text { NACIONAL }\end{array}$ \\
\hline \multirow[t]{2}{*}{$\begin{array}{l}\text { ENMIENDAS CONSTITUCIONALES: (Las } \\
\text { diez primeras el } 15 \text { de diciembre de } \\
\text { 1791). }\end{array}$} & & & $\begin{array}{l}\text { IX.- DE LA INSTRUCCIÓN PÚBLICA, } \\
\text { POLICÍA, COMERCIO Y AGRICULTURA }\end{array}$ & Titulo IX: DE LA INSTRUCCION PUBLICA \\
\hline & & & & $\begin{array}{l}\text { Titulo X: DE LA OBSERVANCIA DE LA } \\
\text { CONSTITUCION Y MODO DE PROCEDER } \\
\text { PARA HACER VARIACIONES EN ELLA }\end{array}$ \\
\hline
\end{tabular}

\footnotetext{
${ }^{65}$ En esta Constitución no se establecen artículos o capítulos y secciones como suele ser costumbre en este tipo de documentos. El documento base fue acompañado de al menos cinco oficios, manifiestos, discursos y relaciones que conforman una unidad.

${ }^{66}$ Cada artículo consta de diversas secciones y éstas a su vez tienen algunos numerales.

${ }^{67}$ El proyecto de Calisto Miranda integra el Legislativo con el Ejecutivo y para el efecto propone un Senado Supremo de Gobernador del Reino (Ejecutivo).
} 